Atmos. Chem. Phys., 12, 1881-1901, 2012

www.atmos-chem-phys.net/12/1881/2012/

doi:10.5194/acp-12-1881-2012

(C) Author(s) 2012. CC Attribution 3.0 License.

\title{
Study of OH-initiated degradation of 2-aminoethanol
}

\author{
M. Karl ${ }^{1}$, C. Dye ${ }^{1}$, N. Schmidbauer ${ }^{1}$, A. Wisthaler ${ }^{2}$, T. Mikoviny ${ }^{2}$, B. D’Anna ${ }^{3}$, M. Müller ${ }^{3}$, E. Borrás ${ }^{4}$, E. Clemente ${ }^{4}$, \\ A. Muñoz ${ }^{4}$, R. Porras ${ }^{4}$, M. Ródenas ${ }^{4}$, M. Vázquez ${ }^{4}$, and T. Brauers ${ }^{5}$ \\ ${ }^{1}$ Norwegian Institute for Air Research, NILU, Kjeller, Norway \\ ${ }^{2}$ Institut für Ionenphysik und Angewandte Physik, Universität Innsbruck, Innsbruck, Austria \\ ${ }^{3}$ IRCELYON, Université Lyon 1, Villeurbanne, France \\ ${ }^{4}$ Instituto Universitario CEAM-UMH - EUPHORE, Paterna - Valencia, Spain \\ ${ }^{5}$ Institut für Energie- und Klimaforschung, IEK-8, Forschungszentrum Jülich, Jülich, Germany
}

Correspondence to: M. Karl (mka@nilu.no)

Received: 21 July 2011 - Published in Atmos. Chem. Phys. Discuss.: 12 October 2011

Revised: 29 January 2012 - Accepted: 3 February 2012 - Published: 17 February 2012

\begin{abstract}
The degradation of 2-aminoethanol (MEA) by the hydroxyl radical $(\mathrm{OH})$ was studied in the European Photoreactor (EUPHORE), a large outdoor environmental chamber. High-Temperature Proton-Transfer-Reaction Mass Spectrometry (HT-PTR-MS) and Fast Fourier Transform Infrared (FT-IR) were used to follow concentrations of reactants in the gas phase. Aerosol mass concentrations were tracked with Aerosol Mass Spectrometry (AMS). The chamber aerosol model MAFOR was applied to quantify losses of MEA to the particle phase. The rate constant $k(\mathrm{OH}+\mathrm{MEA})$ was determined relative to the rate constant of the 1,3,5trimethylbenzene reaction with $\mathrm{OH}$ and was found to be $(9.2 \pm 1.1) \times 10^{-11} \mathrm{~cm}^{3}$ molecule ${ }^{-1} \mathrm{~s}^{-1}$, and thus the reaction between $\mathrm{OH}$ radicals and MEA proceeds a factor of 2-3 faster than estimated by structure-activity relationship (SAR) methods. Main uncertainty of the relative rate determination is the unknown temporal behaviour of the loss rate of MEA to chamber wall surfaces during the sunlit experiments. Nucleation and growth of particles observed in the experiments could be reproduced by the chamber model that accounted for condensation of gaseous oxidation products, condensation of ethanolaminium nitrate and nucleation involving MEA and nitric acid.
\end{abstract}

\section{Introduction}

2-Aminoethanol $\left(\mathrm{H}_{2} \mathrm{NCH}_{2} \mathrm{CH}_{2} \mathrm{OH}\right.$; MEA) is one of the most attractive absorption solvents for the removal of carbon dioxide $\left(\mathrm{CO}_{2}\right)$ from flue gases (Rochelle, 2009) and is regarded as industrial benchmark compound (Puxty et al., 2009; Lepaumier et al., 2009) for the $\mathrm{CO}_{2}$ absorption performance in Carbon Capture Systems (CCS). Other industrial uses are mainly as corrosion inhibitor in water-based metalworking fluids (Geier et al., 2004). It is also a common ingredient of consumer products, such as detergents, degreasers, disinfectants, personal care products and pharmaceutical products (DiGuilio et al., 1992; Dow Chemicals, 2011). MEA is a natural component in plants and animals: it is the second most abundant head group for phospholipids in cell membranes and is thus one of the most important building blocks in nature (e.g. Bakovic et al., 2007). An overview of anthropogenic and natural atmospheric sources of various aliphatic, heterocyclic and aromatic amines is given in the recent review by Ge et al. (2011a).

The use of MEA as an absorption solvent in postcombustion $\mathrm{CO}_{2}$ capture is accompanied by losses of the amine by vaporization due to its relatively high vapour pressure of $30 \mathrm{~Pa}$ at $20^{\circ} \mathrm{C}$ (Kapteina et al., 2005). A substance with sufficiently high vapour pressure will leave the top of the absorber column very easily together with the treated gas. 
MEA emissions from $\mathrm{CO}_{2}$ capture vary strongly depending on operating conditions, for example the temperature of the absorber top. In addition, a water wash or mist eliminator installed at the top section of the absorber will substantially reduce volatility losses from the absorber. Post-combustion emissions are between $0.3 \mathrm{~kg}$ and $0.8 \mathrm{~kg}$ MEA per tonne $\mathrm{CO}_{2}$ captured without water-wash (Goff and Rochelle, 2004), while highly efficient three-stage water-wash reduces the emissions approximately to $0.02 \mathrm{~kg}$ MEA per tonne $\mathrm{CO}_{2}$ captured (Koornneef et al., 2008; Thitakamol et al., 2007). Typically, a $\mathrm{CO}_{2}$ capture plant, that removes $1 \mathrm{Mt} \mathrm{CO}_{2}$ per year from flue gas, emits between 1 ppmv and 4 ppmv MEA in the exhaust gas with single-stage water wash systems (Rao and Rubin, 2002; NVE, 2006), corresponding to about $80 \mathrm{t}$ per year (Veltman et al., 2010).

Once released to the atmosphere, MEA will react during daylight mainly with the hydroxyl $(\mathrm{OH})$ radical. It is known that the atmospheric oxidation of amines can lead to the formation of potentially toxic compounds such as nitrosamines, nitramines, and amides (Pitts et al., 1978; Grosjean, 1991) which are of public concern. The atmospheric oxidation of MEA with $\mathrm{OH}$-radicals is initiated by $\mathrm{H}$-abstraction. Abstraction of $\mathrm{H}$-atoms from the $-\mathrm{NH}_{2}$ group may lead to the formation of nitrosamine and nitramines. However, previous experimental studies in the European Photochemical Reactor (EUPHORE) have shown that less than $10 \%$ of the reaction between $\mathrm{OH}$ and MEA takes place at $-\mathrm{NH}_{2}$ (Nielsen et al., 2011). While the nitramine of MEA, 2-nitroamino ethanol $\left(\mathrm{O}_{2} \mathrm{NNHCH}_{2} \mathrm{CH}_{2} \mathrm{OH}\right)$, was observed with a product yield between $0.3 \%$ and $1.5 \%$, the nitrosamine of MEA, 2-nitroso amino ethanol $\left(\mathrm{ONNHCH}_{2} \mathrm{CH}_{2} \mathrm{OH}\right)$, was not detected (Nielsen et al., 2011). In a recent study of the environmental impact of MEA emissions from $\mathrm{CO}_{2}$ capture, atmospheric dispersion calculations for a "worst case" situation (i.e. no degradation of MEA and its products in air, water and soil) revealed, that nitramines emitted with a fraction of only $1 \%$ of the MEA emissions could be problematic for the aquatic environment within an area of $40 \times 40 \mathrm{~km}^{2}$ around a power plant equipped with $\mathrm{CO}_{2}$ post combustion emitting 40 tonnes MEA per year (Karl et al., 2011a). To our knowledge, toxic effects of 2-nitroamino ethanol have not been studied until now. However, available data for primary and secondary N-nitro alkylamines strongly suggests that these can have mutagenic and carcinogenic effects (Goodall and Kennedy, 1976; Mirvish et al., 1980; Suzuki et al., 1985; Scherf et al., 1989; Hassel et al., 1990).

The reaction rate of 2-aminoethanol with $\mathrm{OH}$ has not been studied experimentally to date. This may be largely due to experimental difficulties with respect to its tendency to "stick" to Teflon (and other) surfaces and its high propensity to form aerosol particles (Carter, 2008; Nielsen et al., 2010). Estimates using structure-activity relationship (SAR) methods (Kwok and Atkinson, 1995; Meylan and Howard, 2003) indicate values in the range of $3-4 \times 10^{-11} \mathrm{~cm}^{3}$ molecule ${ }^{-1} \mathrm{~s}^{-1}$ for the rate constant of the $\mathrm{OH}+$ MEA reaction. Carter (2008) report a value of $4.4 \times 10^{-11} \mathrm{~cm}^{3}$ molecule ${ }^{-1} \mathrm{~s}^{-1}$ estimated using SAR and group-additivity parameters of the SAPRC-07 chemical mechanism (Carter, 2010; http://www.cert.ucr.edu/ carter/ SAPRC).

Gas-phase aliphatic amines may play a significant role in secondary aerosol formation via photo-oxidation and gasto-particle conversion in regions with high amine concentrations in air (Angelino et al., 2001; Murphy et al., 2007; Sorooshian et al., 2008; Smith et al., 2010). Aerosol particles forming in the atmospheric oxidation of amines can be either organic salt particles or non-salt particles, the latter are commonly referred to as secondary organic aerosol (SOA). Since amines are basic compounds, they can react with strong acids, commonly present in the atmosphere, such as nitric acid $\left(\mathrm{HNO}_{3}\right)$ and sulphuric acid, to form amine salts, which partition into the aerosol phase. This process can be viewed as a loss process of amines from the gas phase. However, the acid-base reaction of amines with $\mathrm{HNO}_{3}$ is reversible and an equilibrium exists between the salt, the amine and $\mathrm{HNO}_{3}$ (Murphy et al., 2007).

Accurate knowledge of the $\mathrm{OH}$-reaction rate constant is essential for the correct prediction of atmospheric concentrations of hazardous products forming in the degradation of MEA and consequently for estimating the impact of MEA emissions from $\mathrm{CO}_{2}$ capture on health and environment. In this study we report on experimental determination of the rate constant for the reaction of $\mathrm{OH}$ with MEA relative to the reaction rate constant with 1,3,5-trimethylbenzene (TMB). We also present a mechanism for atmospheric modelling the $\mathrm{OH}$-initiated degradation of MEA which has been tested with chamber data obtained during a series of MEA photooxidation experiments.

\section{Experimental}

\subsection{EUPHORE}

Photo-oxidation experiments with MEA were carried out at the EUPHORE simulation chamber in Valencia, Spain, in the period of 26-30 July 2010. The EUPHORE facility comprises two half-spherical outdoor chambers constructed of a steel frame covered with Teflon foil, each with volume of approximately $200 \mathrm{~m}^{3}$ (Becker, 1996; Vera et al., 2011; http://euphore.es/). This design has a surface/volume ratio close to one that is optimum to minimize possible losses of MEA by adsorption to the chamber walls. The experimental reactor is shielded by two retractable half-spherical protective housings which, when closed, also exclude sunlight from the reactors. To achieve homogeneous concentrations, two mixing fans are placed inside the chamber. The floor is water-cooled to minimise solar heating and the chambers are equipped with air purification and drying which provides dry air. Outside air is pressurised by means of a screw 
compressor to 6 bar. The compressed air is passed through a condensate trap to separate water and oil from the air and passed later through heat exchanger to reduce the absolute water content. The air is dried in absorption driers and passes a special charcoal filter to remove nitrogen oxides $\left(\mathrm{NO}_{\mathrm{x}}\right)$, the oil vapour and non-methane hydrocarbons (NMHC). The cleaned air has the $\mathrm{NO}_{\mathrm{x}}$ level below the detection limit of the instruments (i.e. $50 \mathrm{pptv}$ ), total NMHC concentration below $1 \mathrm{ppbv}$, carbon monoxide (CO) and methane are not completely removed and their concentration is at environmental level, and show high daily variability, water vapour is removed to a value $<0.1 \mathrm{mbar}$, i.e. $-50^{\circ} \mathrm{C}$ dew point.

\subsection{Instrumentation}

The analysis in EUPHORE was performed using the following instrumentation:

- O3-ML9810 (Teledyne Monitor Labs, USA). The principle of operation of the ozone $\left(\mathrm{O}_{3}\right)$ monitor is a non dispersive ultraviolet photometer, which alternatively switches a selective ozone scrubber in and out of the measuring stream, and computes the ratio of transmitted light. A mercury vapour lamp is used as the light source $(254 \mathrm{~nm})$ and a solar blind vacuum photodiode is used as detector. The monitor measures $\mathrm{O}_{3}$ with an accuracy of $\pm 2.5 \%(1-\sigma)$ and has a detection limit of 250 pptv $(1-\sigma)$.

- NO -ECO-ALppt 77312 (Eco Physics, Switzerland). This monitor measures the nitrogen oxide (NO), nitrogen dioxide $\left(\mathrm{NO}_{2}\right)$ and $\mathrm{NO}_{\mathrm{x}}(\mathrm{ppb})$ concentration directly from the chamber. The detection limit of NO, $\mathrm{NO}_{2}$, and $\mathrm{NO}_{\mathrm{x}}$ is 30 pptv, 50 pptv, and 90 pptv $(1-\sigma)$, respectively. The $\mathrm{O}_{3}$ monitor and the two $\mathrm{NO}_{x}$ monitors have been calibrated with the same gas calibration set-up and therefore have the same accuracy of $\pm 2.5 \%$ $(1-\sigma)$. NOx-ECO-ALppt has two independent units; the analyzer CLD 770 Alppt and the photolytic converter PLC 760. The principle of operation of the CLD 770 Alppt analyzer is the gas phase chemiluminescent reaction of $\mathrm{NO}$ with $\mathrm{O}_{3}$. The photolytic converter PLC 760 performs a selective conversion of $\mathrm{NO}_{2}$ to $\mathrm{NO}$ through photo dissociation with a xenon lamp.

- NO $x_{x}$ API200AU (Teledyne Advanced Pollution Instruments Inc. USA). This instrument measures $\mathrm{NO}_{\mathrm{y}}, \mathrm{NO}_{\mathrm{x}}$, $\mathrm{NO}$, and $\mathrm{NO}_{2}$. For $\mathrm{NO}_{\mathrm{x}}$ the detection limit is $800 \mathrm{pptv}$ $(1-\sigma)$. It measures the light intensity of the chemiluminescent gas phase reaction of $\mathrm{NO}$ with $\mathrm{O}_{3}$. The analyzer samples the gas stream and measures the NO concentration by digitizing the signal from the analyzer's photomultiplier tube (PMT). A valve then routes the sample stream through a converter containing heated molybdenum to reduce any $\mathrm{NO}_{\mathrm{x}}$ present to $\mathrm{NO}$ at $315^{\circ} \mathrm{C}$. Then the analyzer measures the total $\mathrm{NO}_{\mathrm{x}}$ concentration. The
$\mathrm{NO}_{\mathrm{x}}$ and $\mathrm{NO}$ values are subtracted from each other to obtain the $\mathrm{NO}_{2}$ concentration.

- J(NO $\left.\mathrm{NO}_{2}\right)$ Filter Radiometer (Meteorologie Consult $\mathrm{GmbH}$, Glasshütten, Germany). The filter radiometer is installed inside the Teflon chamber, $50 \mathrm{~cm}$ above the chamber floor, to measure the $\mathrm{NO}_{2}$ photolysis frequency. The field of view is $2 \times 180$ degrees $(4 \pi \mathrm{sr})$. Wavelength characteristics are obtained from best fit to the photolysis frequency of the $\mathrm{NO}_{2}$ molecule. Absolute calibration is better than $\pm 5 \%$ with respect to a chemical actinometer and linearity is better than $1 \%$ according to the detector characteristics.

- High-Temperature Proton-Transfer-Reaction Mass Spectrometer (HT-PTR-MS). A HT-PTR-MS (Mikoviny et al., 2010) was used for high time resolution measurements of MEA and 1,3,5-trimethylbenzene. Sample-wetted surfaces of the HT-PTR-MS were kept at $200^{\circ} \mathrm{C}$ to minimize adsorption and desorption effects of MEA. Previous work has shown that the $1 \mathrm{e}^{-2}$ response time of the HT-PTR-MS to MEA is in the 5to-18 s range (Mikoviny et al., 2010). The HT-PTR-MS was interfaced to the EUPHORE chamber via a Sulfinert ${ }^{\circledR}$ passivated stainless steel tube (length: $125 \mathrm{~cm}$, i.d.: $5.33 \mathrm{~mm}$; temperature: $230^{\circ} \mathrm{C}$; flow: $10 \mathrm{slpm}$ ). Instrumental sensitivity for 1,3,5-trimethylbenzene was determined experimentally using a certified gas standard (AiR, Denver, USA). MEA quantification was based on calculated proton transfer reaction rate coefficients (Nielsen et al., 2010). Detection limit of TMB and MEA with the HT-PTR-MS is $100 \mathrm{pptv}$ (Mikoviny et al., 2010). Both compounds can be measured with a $1-\sigma$ precision of $\pm 10 \%$ or better. The $1-\sigma$ accuracy is estimated to be $\pm 10 \%$ for TMB and $\pm 15 \%$ for MEA.

- Fast Fourier Transform Infrared (FT-IR) Spectroscopy. The spectrometer (NICOLET 6700, MCT-detector) is coupled to a long-path multi-reflection cell installed in the chamber for the detection in the IR spectral range $\left(650-4000 \mathrm{~cm}^{-1}\right)$. The gold-coated mirrors of the cell allow a total path length of $554 \mathrm{~m}$. Spectra are collected with resolution $1 \mathrm{~cm}^{-1}$ by averaging 280 scans, resulting in a sampling time of $5 \mathrm{~min}$ per spectrum. Concentrations of sulphur hexafluoride $\left(\mathrm{SF}_{6}\right)$, MEA, and formamide $\left(\mathrm{H}_{2} \mathrm{NCHO}\right)$ during the experiments were determined with analysis software developed at CEAM (Ródenas, 2008) by analysing the IR spectra using calibrated reference spectra collected a priori. For the calibration of gases measured by FT-IR, the compound was injected into the chamber with a syringe in repeated trials. Typical detection limits for the analyzed compounds are a few ppb. Accuracy $(1-\sigma)$ is $\pm 10 \%$ for formamide and $\mathrm{SF}_{6}$. For $\mathrm{SF}_{6}$ the precision is $\pm 3 \%$ based on repeated injections. Quantification of MEA 
was done by cross-calibration against MEA measurements of the HT-PTR-MS instrument with an estimated accuracy of about $\pm 15 \%$.

- Gas chromatography with photo ionisation detector $(G C$-PID). The GC-PID operated using a $30 \mathrm{~m}$ DB624 fused silica capillary column (J\&W Scientific, $0.32 \mathrm{~mm}$ i.d., $1.8 \mathrm{~mm}$ film). Air was sampled from the chamber into a $3 \mathrm{~cm}^{3}$ sampling loop and then injected onto the column. The column was maintained at a constant temperature $\left(120^{\circ} \mathrm{C}\right)$. The GC-PID analyzed TMB with accuracy of $\pm 10 \%(1-\sigma)$ and detection limit of $0.6 \mathrm{ppbv}$.

- PTR-TOF 8000 Proton-Transfer-Reaction Time-ofFlight Mass Spectrometer. A commercial PTR-TOF 8000 mass spectrometer (Ionicon Analytik GmbH, Innsbruck, Austria; Jordan et al., 2009) was used to measure two of the target products from MEA photooxidation, formamide and 2-nitroamino ethanol. Both compounds were detected in their protonated forms at mass-to-charge ratios $(\mathrm{m} / \mathrm{z}) 46.028$ and 107.045 , respectively. Isobaric interferences prevented their specific detection by HTR-PTR-MS. On the other hand, the time response of the PTR-TOF was too slow for kinetic measurements of MEA. Quantification of formamide and 2-nitroamino ethanol was based on calculated proton transfer reaction rate coefficients (Nielsen et al., 2010). It was not experimentally verified that 2 nitroamino ethanol does not generate ionic fragments upon protonation. In addition, adjacent mass peaks in the PTR-TOF spectrum may have led to an overestimation of the small protonated 2-nitroamino ethanol peak. The quantification of 2-nitroamino ethanol should thus be regarded as tentative. The $2-\sigma$ detection limit for 2-nitroamino ethanol at $5 \mathrm{~min}$ signal integration time was 2.5 pptv. The PTR-TOF-MS was interfaced to the chamber via a PEEK capillary tube (length: $220 \mathrm{~cm}$, i.d.: $1.01 \mathrm{~mm}$; temperature: $160^{\circ} \mathrm{C}$; flow: $0.5 \mathrm{slpm}$ ). No sampling line artefact tests were performed.

- Compact Time-of-Flight Aerosol Mass Spectrometer (cTOF AMS). The c-TOF AMS (Drewnick et al., 2005) was employed to characterize the chemical composition of non refractory aerosols. The AMS utilizes thermal flash evaporation of the aerosol followed by electron impact ionization and ion detection by TOF-MS. Measured ions are analyzed using the high resolution data analysis methods described by Müller et al. (2011) and are grouped into chemical species (organics, nitrates, ammonium, sulphates). For quantification, calibrations using ammonium nitrate, ammonium sulphate and MEA nitrate have been performed.
- Tapered Element Oscillating Monitor (TEOM) model 1400a (Ruppercht and Patashnick Co. Inc, Albany, USA). This instrument measures aerosol mass concentration with a $1 \mathrm{~min}$ scan rate. The particles were collected on a replaceable $0.5 \mathrm{~cm}$ diameter filter, which was mounted on an oscillating microbalance, with a sampling flow of $31 \mathrm{~min}^{-1}$, at $27^{\circ} \mathrm{C}$.

- Scanning Mobility Particle Sizer (SMPS), model 3080 (TSI Incorporated, Shoreview, USA). Particle measurements were also made with a SMPS system that consists of a differential mobility analyzer, model 3081, and a condensation particle counter, model 3022A, which measure size distributions in the 11-982 nm diameter range in real time with a $5 \mathrm{~min}$ scan rate. Sheath and aerosol sampling flows were $21 \mathrm{~min}^{-1}$ and $0.301 \mathrm{~min}^{-1}$, respectively.

- Offline analysis of ThermosorbN cartridges. Sample collection with ThermosorbN was performed for a one hour period at a flow rate of approximately $3.31 \mathrm{~min}^{-1}$, and the samples were stored in a freezer until analysis. The exposed tubes were desorbed with $2 \mathrm{ml}$ of a solvent mixture (75\% dichloromethane, $25 \%$ methanol). The sample extract solvent was changed to $0.5 \mathrm{ml} \mathrm{MQ}$-water and the samples were analysed by an Agilent 1100 liquid chromatography system (Agilent Technologies, Waldbronn, Germany), equipped with an auto-sampler, a quaternary pump, an on-line degassing system and a diode array detector (UV). The compound separation was performed using a reversed phase $\mathrm{C} 18$ column (Atlantis dC18, $2.1 \mathrm{~mm}$ ID $\times 150 \mathrm{~mm}$ length, $3 \mu \mathrm{m}$, Waters, Milford USA). A stainless steel inlet filter (Supelco, $0.8 \mu \mathrm{m}$ ) was used in front of the column. The analytical detector was a Micromass LCT orthogonal-acceleration time-of-flight (TOF) mass spectrometer (MS) equipped with a Z-spray electrospray ion source and a $4 \mathrm{GHz}$ time to digital converter (TDC) (Micromass Ltd, Wythenshawe, Manchester, UK). The mobile phase consisted of water and had a flow rate of $0.2 \mathrm{ml} \mathrm{min}^{-1}$. The 2nitroamino ethanol was detected with negative electrospray ionisation, and the electrospray source parameters were optimised as the following: sample cone $16 \mathrm{~V}$, capillary voltage of $3.0 \mathrm{kV}$, extraction cone $3 \mathrm{~V}$, source temperature $120^{\circ} \mathrm{C}$, desolvation temperature $350^{\circ} \mathrm{C}$, zero cone gas flow and desolvation gas flow of $4141 \mathrm{~h}^{-1}$. The pusher frequency was operated in automatic mode. The data processing and instrument (HPLC-HRMS) control were performed by the MassLynx software, and quantification was performed on the ion $[\mathrm{M}-\mathrm{H}]^{-}$at $(\mathrm{m} / \mathrm{z}) 105.0300$ with the external standard method using a calibration standard of 2-nitroamino ethanol in water $\left(250 \mathrm{ng} \mathrm{ml}^{-1}\right)$. The 2-nitroamino ethanol precision is estimated to be $\pm 7 \%$ RSD with an accuracy of $\pm 10 \%$ RSD. 


\subsection{Experiments}

Two experiments were performed on the relative determination of the rate constant (E1 and E2) and one experiment was performed to test the mechanism for $\mathrm{OH}$-initiated atmospheric degradation of MEA (E3). Various amounts of NO and $\mathrm{NO}_{2}, 400 \mu \mathrm{l} \mathrm{MEA}$, and a known amount of TMB (only in E1 and E2) were injected into the dark chamber and after approximately one hour the canopy of the chamber was opened and the mixture was exposed to sunlight. Initial mixing ratio of TMB in E1 and E2 was about 200 ppbv. MEA was injected with a Harvard 22 syringe pump system with air stream heating (Fournier et al., 2008; with modifications) which allows for transfer of a known amount of MEA into the chamber. However, MEA losses during injection which occur between the outlet of the syringe and the inlet of the chamber can be substantial and it was not possible to quantify the lost amount. The quantification of MEA mixing ratios in the chamber air relied on measurements with the HTPTR-MS and FT-IR instruments. Maximum MEA mixing ratios were reached about $15 \mathrm{~min}$ after start of the injection. Initial concentrations of reactants and ranges of $\mathrm{O}_{3}, \mathrm{NO}$ and $\mathrm{NO}_{2}$ concentrations in experiments E1-E5 are presented in Table 1 together with average relative humidity $(\mathrm{RH})$ and temperature $(T)$. Time series of $\mathrm{O}_{3}, \mathrm{NO}, \mathrm{NO}_{2}$ and the photolysis frequency of $\mathrm{NO}_{2}, j\left(\mathrm{NO}_{2}\right)$, during $\mathrm{E} 1$ and $\mathrm{E} 2$ are shown in Fig. 1.

\section{Chamber model description and mechanism}

In the chamber, MEA is subject to the following loss processes:

$$
\begin{aligned}
\mathrm{H}_{2} \mathrm{NCH}_{2} \mathrm{CH}_{2} \mathrm{OH}+\mathrm{OH} & \stackrel{k_{1}}{\longrightarrow} \text { products } \\
\mathrm{H}_{2} \mathrm{NCH}_{2} \mathrm{CH}_{2} \mathrm{OH} & \stackrel{k_{\text {dil }}}{\longrightarrow} \\
\mathrm{H}_{2} \mathrm{NCH}_{2} \mathrm{CH}_{2} \mathrm{OH} & \stackrel{k_{\text {wall }}}{\longrightarrow}
\end{aligned}
$$

$$
\begin{aligned}
& \mathrm{H}_{2} \mathrm{NCH}_{2} \mathrm{CH}_{2} \mathrm{OH}+\mathrm{HNO}_{3} \stackrel{K_{p}}{\longleftrightarrow} \\
& \mathrm{H}_{3} \mathrm{~N}^{+} \mathrm{CH}_{2} \mathrm{CH}_{2} \mathrm{OHNO}_{3}^{-} \text {(s) }
\end{aligned}
$$

The aim of this study is to determine the rate constant $k_{1}$ of Reaction (R1) between MEA and OH radicals. During the experiments, all compounds are diluted by the replenishment flow. The replenishment flow is added to ensure a constant chamber volume by replacing air that is lost due to outtake by the connected instruments and through the Teflon foil. The first order loss rate constant $k_{\text {dil }}$ for dilution was determined from the first order decay of $\mathrm{SF}_{6}$ gas during the experiments. The loss of MEA to chamber walls can be described as a first order loss. The first order loss rate $k_{\text {wall }}$ was determined in
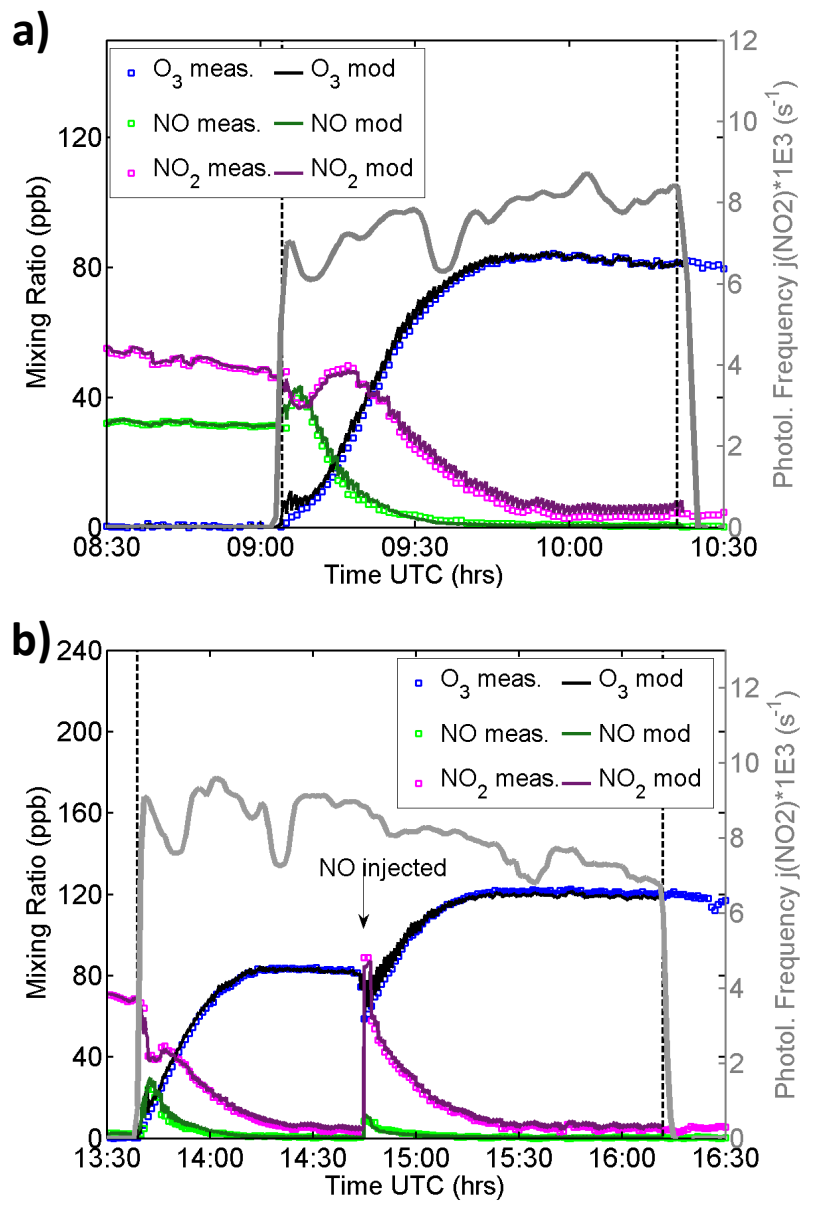

Fig. 1. Measured and modelled time series of $\mathrm{O}_{3}, \mathrm{NO}_{2}$, and $\mathrm{NO}$ mixing ratios in (a) experiments $\mathrm{E} 1$ and (b) experiment $\mathrm{E} 2$. The model was constrained by measured $\mathrm{O}_{3}, \mathrm{NO}_{2}$, and $\mathrm{NO}$ concentrations and therefore modelled mixing ratios coincide with measured ones. Photolysis frequency of $\mathrm{NO}_{2}$ (scaled by $1 \times 10^{3}$ ) indicated by grey-shaded line. Vertical dashed lines indicate beginning and end of the sunlit experiment.

our study from the decay of MEA in the period after injection of MEA into the dark chamber starting at the time when homogeneous distribution in the chamber volume was reached until the time of opening the canopy. MEA reacts in thermodynamic solid-gas equilibrium with $\mathrm{HNO}_{3}$ to form solid aminium nitrate (Reaction R4) which partitions to the aerosol phase. A detailed chamber aerosol model has been used to derive the rate for the loss of MEA to particles, $k_{\text {particles, }}$, as function of time (see Sects. 3.5 and 3.6).

\subsection{Model description}

Modelling of chamber experiments was done using the multicomponent aerosol dynamics model MAFOR (Marine Aerosol Formation model) version 1.3 which includes gas phase and aqueous phase chemistry in addition to aerosol 
Table 1. Initial mixing ratios of reactants (at start of the experiment), ranges of the mixing ratios of $\mathrm{O}_{3}, \mathrm{NO}, \mathrm{NO}_{2}$, average relative humidity and average temperature in the MEA photo-oxidation experiments.

\begin{tabular}{|c|c|c|c|c|c|c|c|c|c|}
\hline \multirow[b]{2}{*}{ Exp. } & \multirow[b]{2}{*}{ Date } & \multicolumn{3}{|c|}{ Initial mixing ratio } & \multicolumn{3}{|c|}{ Range of mixing ratio } & \multirow[b]{2}{*}{$\begin{array}{l}\text { RH } \\
(\%)\end{array}$} & \multirow[b]{2}{*}{$\begin{array}{c}T \\
(\mathrm{~K})\end{array}$} \\
\hline & & $\begin{array}{r}\text { MEA } \\
\text { (ppbv) }\end{array}$ & $\begin{array}{r}\text { TMB } \\
\text { (ppbv) }\end{array}$ & $\begin{array}{r}\mathrm{NO}_{\mathrm{x}} \\
(\mathrm{ppbv})\end{array}$ & $\begin{array}{r}\mathrm{O}_{3} \\
\text { (ppbv) }\end{array}$ & $\begin{array}{r}\mathrm{NO}_{2} \\
\text { (ppbv) }\end{array}$ & $\begin{array}{r}\text { NO } \\
\text { (ppbv) }\end{array}$ & & \\
\hline E1 & 28.07 .2010 & 255 & 193 & 78 & $0-80$ & $5-55$ & $0-30$ & $7 \pm 1$ & $304.9 \pm 2.0$ \\
\hline E2 & 28.07.2010 & 292 & 199 & 70 & $0-120$ & $5-70$ & 2 & $10 \pm 1$ & $307.4 \pm 1.6$ \\
\hline E3 & 27.07.2010 & 410 & - & 406 & $10-25$ & $140-280$ & $20-140$ & $11 \pm 6$ & $306.9 \pm 0.1$ \\
\hline E4 & 15.05.2009 & 618 & - & 30 & $0-70$ & 0-20 & $0-30$ & $2 \pm 1$ & $300.3 \pm 1.3$ \\
\hline E5 & 11.05.2009 & 83 & - & 1170 & $<1$ & $340-460$ & $690-740$ & $3 \pm 1$ & $299.5 \pm 1.8$ \\
\hline
\end{tabular}

dynamics (Karl et al., 2011b). In MAFOR, the general dynamic equation of the aerosol is solved using a sectional approach with a fixed grid. Mass transfer of gas molecules to particles is calculated using the Analytical Predictor of Condensation scheme (Jacobson, 1997). The various aerosol dynamical processes are treated by calculation of the particle number concentration and component mass concentrations of each size section as functions of time. The number of size sections can be selected by the user; in this study 100 size bins were used to represent the aerosol size distribution ranging from $1 \mathrm{~nm}$ to $10 \mu \mathrm{m}$ diameter sizes.

The detailed gas phase chemistry scheme of the model based on the Module Efficient Calculating the Chemistry of the Atmosphere (MECCA) (Sander et al., 2005; Sander et al., 2011) includes chemistry of C2-C4 alkanes, propene, isoprene and dimethyl sulphide (Karl et al., 2007). For the purpose of this study, a chemistry mechanism for the $\mathrm{OH}$ initiated oxidation of MEA (described in Sect. 3.3) and a simple scheme for TMB were added (Table 2). A simplified treatment of the TMB chemistry is considered to be adequate since it is not intended to model concentrations of TMB oxidation products in this study. Photolysis frequencies are calculated using the method of Landgraf and Crutzen (1998) and data on absorption coefficients and quantum yields recommended by the Jet Propulsion Laboratory (JPL) Evaluation no. 15 (Sander et al., 2006).

The current mechanism of MAFOR v1.3 contains 383 reactions and 221 compounds in the gas phase. The kinetic pre-processor (KPP; http://people.cs.vt.edu/ asandu/ Software/Kpp/) solver package is used to generate Fortran95 code for the chemistry module and the Rosenbrock 3 solver is used for integration the differential equation system of gas phase reactions (Sandu et al., 1997; Sandu and Sander, 2006). Change of number and mass concentration of particles is solved subsequent to the integration of the gas phase/liquid phase chemistry.

\subsection{Chamber sources and losses}

Parameterizations of the chamber wall sources of nitrous acid $(\mathrm{HONO}), S_{\mathrm{HONO}}$, and formaldehyde $(\mathrm{HCHO})$ are included in the model. The photolysis of HONO in sunlight was the main source of $\mathrm{OH}$ during the experiments in EUPHORE. The $\mathrm{HONO}$ wall source is parameterized as function of $j\left(\mathrm{NO}_{2}\right)$, temperature and relative humidity for dry and humid conditions (Zádor et al., 2006). The light-dependent source of formaldehyde (Zádor et al., 2006) is used in the model. First order wall loss rates for $\mathrm{O}_{3}, \mathrm{NO}_{2}$ and $\mathrm{HNO}_{3}$ of $3 \times 10^{-6} \mathrm{~s}^{-1}$, $1.15 \times 10^{-5} \mathrm{~s}^{-1}$ and $8.2 \times 10^{-5} \mathrm{~s}^{-1}$, respectively, and a $\mathrm{OH}-$ to- $\mathrm{HO}_{2}$ conversion rate of $8.4 \mathrm{~s}^{-1}$ to account for the background reactivity of the chamber (Bloss et al., 2005a), have been used in the simulation of experiments. Loss rates for $\mathrm{O}_{3}$ and $\mathrm{NO}_{2}$ were not relevant in our study because monitored time series of $\mathrm{NO}_{2}$ and $\mathrm{O}_{3}$ concentrations were used as model input in simulations of the experiments. Further, measured time series of $\mathrm{NO}$ concentrations, temperature and $j\left(\mathrm{NO}_{2}\right)$ were used to constrain the model. A size-dependent parameterization of the wall loss of particles in the chamber is included in the model to reproduce the particle loss. The parameterization is according to Naumann (2003) and takes into account the geometry of the EUPHORE chamber.

\subsection{Atmospheric mechanism for the $\mathrm{OH}$-initiated degradation of MEA}

The mechanism for the OH-initiated oxidation of MEA used in the model simulations is provided in Table 3. The mechanism has been constructed during the project ADA-2009 ("Atmospheric Degradation of Amines, 2009"; Nielsen et al., 2010), based on quantum chemical calculations (Bråten et al., 2008), SAR estimated rate constants and adjusted to fit experimental data in MEA photo-oxidation experiments in EUPHORE. The scheme contains 17 reactions and 17 compounds in the gas phase.

According to Nielsen et al. (2011), the formation of the following products was unambiguously attributed to the $\mathrm{OH}$-initiated oxidation of MEA in the EUPHORE experiments: formaldehyde $(\mathrm{HCHO})$, formamide $\left(\mathrm{H}_{2} \mathrm{NCHO}\right)$, 
Table 2. Simplified reaction mechanism for 1,3,5-trimethylbenzene used in this study. The degree of detail of this mechanism corresponds to the aromatic hydrocarbon chemistry scheme by Jacobson (1997).

\begin{tabular}{|c|c|c|c|c|c|}
\hline No. & Reaction & & & Rate constant ${ }^{\mathrm{a}}$ & Reference \\
\hline 1 & $\mathrm{TMB}+\mathrm{OH}$ & $\rightarrow$ & $\begin{array}{l}0.79 \mathrm{TMBADO} 2+0.21 \mathrm{AROPEN}+0.03 \mathrm{TMBO} 2+0.05 \mathrm{CRES} \\
+0.05 \mathrm{HO}_{2}+0.04 \mathrm{TMBSOA}\end{array}$ & $4.40 \times 10^{-12} \exp (738 / T)$ & Aschmann et al. (2006) \\
\hline 2 & $\mathrm{TMBO} 2+\mathrm{NO}$ & $\rightarrow$ & $0.105 \mathrm{TMBNIT}+0.895 \mathrm{TMBO}+0.895 \mathrm{NO}_{2}$ & $2.54 \times 10^{-12} \exp (360 / T)$ & $\mathrm{MCM}^{\mathrm{b}}$ \\
\hline 3 & $\mathrm{TMBO}+\mathrm{O}_{2}$ & $\rightarrow$ & $1.28 \mathrm{CRES}+1.28 \mathrm{HO}_{2}$ & $9.5 \times 10^{-15}$ & $\mathrm{MCM}^{\mathrm{b}}$ \\
\hline 4 & $\mathrm{TMBADO} 2+\mathrm{O}_{2}$ & $\rightarrow$ & $0.157 \mathrm{TMBNIT}+0.843 \mathrm{TMBADO}+0.843 \mathrm{NO}_{2}$ & $2.54 \times 10^{-12} \exp (360 / T)$ & $\mathrm{MCM}^{\mathrm{b}}$ \\
\hline 5 & TMBADO2 & $\rightarrow$ & 1.2 TMBADO + 0.51 CRES + 0.51 BZALD + 1.2 MGLYOX & $2.4 \times 10^{-12} \times\left[\mathrm{RO}_{2}\right]$ & $\mathrm{MCM}^{\mathrm{b}}$ \\
\hline 6 & TMBADO & $\rightarrow$ & $\mathrm{MGLYOX}+\mathrm{HO}_{2}+0.5 \mathrm{AROPEN}+0.5 \mathrm{DCB} 1$ & $1.0 \times 10^{6}$ & $\mathrm{MCM}^{\mathrm{b}}$ \\
\hline 7 & $\mathrm{AROPEN}+\mathrm{OH}$ & $\rightarrow$ & AROPPX $+\mathrm{CH}_{3} \mathrm{CO}_{3}+\mathrm{HO}_{2}+\mathrm{CO}$ & $3.0 \times 10^{-11}$ & Jacobson (2007) \\
\hline 8 & AROPPX + NO & $\rightarrow$ & $\mathrm{NO}_{2}+\mathrm{HCHO}+\mathrm{HO}_{2}+\mathrm{CO}$ & $8.1 \times 10^{-12}$ & Jacobson (2007) \\
\hline 9 & $\mathrm{CRES}+\mathrm{OH}$ & $\rightarrow$ & $0.24 \mathrm{BZO}+0.76 \mathrm{CRESO} 2+\mathrm{H}_{2} \mathrm{O}$ & $1.7 \times 10^{-12} \exp (950 / T)$ & Carter (2010) \\
\hline 10 & $\mathrm{CRESO} 2+\mathrm{NO}$ & $\rightarrow$ & 0.58 AROPEN +0.58 ARACID $+\mathrm{NO}_{2}+\mathrm{HO}_{2}$ & $4.0 \times 10^{-12}$ & Jacobson (2007) \\
\hline 11 & $\mathrm{BZO}+\mathrm{NO}_{2}$ & $\rightarrow$ & BZN & $2.3 \times 10^{-12} \exp (150 / T)$ & Carter (2010) \\
\hline 12 & AROPEN $+h v$ & $\rightarrow$ & $\mathrm{CH}_{3} \mathrm{C}(\mathrm{O}) \mathrm{OO}+\mathrm{CO}+\mathrm{HO}_{2}$ & $j(\mathrm{MGLYOX})$ & $\mathrm{MCM}^{\mathrm{c}}$ \\
\hline 13 & $\mathrm{BZALD}+h v$ & $\rightarrow$ & $\mathrm{PHO} 2+\mathrm{CO}+\mathrm{HO}_{2}$ & $j$ (MGLYOX) & $\mathrm{MCM}^{\mathrm{c}}$ \\
\hline
\end{tabular}

${ }^{a}$ Rate constant in units $\mathrm{cm}^{3}$ molecule ${ }^{-1} \mathrm{~s}^{-1}$, photolysis rates in units $\mathrm{s}^{-1}$. ${ }^{\mathrm{b}}$ Rate constant and branching ratio adopted from the Master Chemical Mechanism (MCM) $\mathrm{v} 3.1$ (Bloss et al., 2005b), available at http://mcm.leeds.ac.uk/MCMv3.1. ${ }^{\mathrm{c}}$ Photolysis rate parameterization as $J(34)$ in MCM v3.1.

Table 3. Mechanism for OH-initiated oxidation of MEA used to simulate chamber experiments on the photo-oxidation of MEA ${ }^{\mathrm{a}}$. Reactions with gas-phase products and temperature dependent rate constants.

\begin{tabular}{|c|c|c|c|c|c|}
\hline No. & Reaction & & & Rate constant ${ }^{\mathrm{b}}$ & Reference \\
\hline 1 & $\mathrm{NH}_{2} \mathrm{CH}_{2} \mathrm{CH}_{2} \mathrm{OH}+\mathrm{OH}$ & $\rightarrow$ & $\begin{array}{l}0.05 \mathrm{H}_{2} \mathrm{NCH}_{2} \mathrm{CHO}+0.8 \mathrm{MEABO} 2 \\
+0.15 \mathrm{MEAN}+0.05 \mathrm{HO}_{2}\end{array}$ & $3.58 \times 10^{-11}$ & EPI Suite ${ }^{\mathrm{TM}_{\mathrm{V}} 4.0}$ \\
\hline 2 & $\mathrm{H}_{2} \mathrm{NCH}_{2} \mathrm{CHO}+\mathrm{OH}$ & $\rightarrow$ & $0.8 \mathrm{H}_{2} \mathrm{NCH}_{2} \mathrm{CO}_{3}+0.2 \mathrm{H}_{2} \mathrm{NCHO}_{2} \mathrm{CHO}+\mathrm{H}_{2} \mathrm{O}$ & $4.83 \times 10^{-11}$ & EPI Suite ${ }^{\mathrm{TM}} \mathrm{v} 4.0$ \\
\hline 3 & $\mathrm{H}_{2} \mathrm{NCH}_{2} \mathrm{CO}_{3}+\mathrm{NO}$ & $\rightarrow$ & $\mathrm{MMAO} 2+\mathrm{CO}_{2}+\mathrm{NO}_{2}$ & $8.10 \times 10^{-12} \exp (270 / T)$ & $\mathrm{MCM}^{\mathrm{c}}$ \\
\hline 4 & $\mathrm{H}_{2} \mathrm{NCHO}_{2} \mathrm{CHO}+\mathrm{NO}$ & $\rightarrow$ & $\mathrm{H}_{2} \mathrm{NCOCHO}+\mathrm{HO}_{2}+\mathrm{NO}_{2}$ & $1.7 \times 10^{-11}$ & This work, estimate \\
\hline 5 & $\mathrm{H}_{2} \mathrm{NCOCHO}+\mathrm{OH}$ & $\rightarrow$ & $\mathrm{H}_{2} \mathrm{NCOCO}_{3}+\mathrm{H}_{2} \mathrm{O}$ & $1.47 \times 10^{-11}$ & EPI Suite ${ }^{\mathrm{TM}} \mathrm{v} 4.0$ \\
\hline 6 & $\mathrm{H}_{2} \mathrm{NCOCO}_{3}+\mathrm{NO}$ & $\rightarrow$ & $\mathrm{H}_{2} \mathrm{NCHO}+\mathrm{CO}_{2}+\mathrm{NO}_{2}$ & $8.10 \times 10^{-12} \exp (270 / T)$ & $\mathrm{MCM}^{\mathrm{c}}$ \\
\hline 7 & $\mathrm{MEABO} 2+\mathrm{NO}$ & $\rightarrow$ & $\mathrm{MEABO}+\mathrm{NO}_{2}$ & $2.54 \times 10^{-12} \exp (360 / T)$ & $\mathrm{MCM}^{\mathrm{c}}$ \\
\hline 8 & $\mathrm{MEABO}+\mathrm{O}_{2}$ & $\rightarrow$ & $\mathrm{H}_{2} \mathrm{NCOCH}_{2} \mathrm{OH}+\mathrm{HO}_{2}$ & $2.4 \times 10^{-15}$ & This work, estimate \\
\hline 9 & MEABO & $\rightarrow$ & $\mathrm{H}_{2} \mathrm{NCHO}+\mathrm{HCHO}$ & $2.0 \times 10^{5}$ & This work, estimate \\
\hline 10 & $\mathrm{H}_{2} \mathrm{NCHO}+\mathrm{OH}$ & $\rightarrow$ & $\mathrm{HNCO}+\mathrm{HO}_{2}$ & $4.0 \times 10^{-12}$ & Barnes et al. (2010) \\
\hline 11 & $\mathrm{H}_{2} \mathrm{NCOCH}_{2} \mathrm{OH}+\mathrm{OH}$ & $\rightarrow$ & $\mathrm{H}_{2} \mathrm{NCOCHO}+\mathrm{HO}_{2}$ & $4.59 \times 10^{-12}$ & EPI Suite ${ }^{\mathrm{TM}} \mathrm{v} 4.0$ \\
\hline 12 & $\mathrm{MEAN}+\mathrm{NO}_{2}$ & $\rightarrow$ & $0.5 \mathrm{MEANNO} 2+0.5 \mathrm{HNCHCH}_{2} \mathrm{OH}+0.5 \mathrm{HONO}$ & $1.4 \times 10^{-13}$ & Nielsen et al. $(2010)^{\mathrm{d}}$ \\
\hline 13 & $\mathrm{MEAN}+\mathrm{O}_{2}$ & $\rightarrow$ & $\mathrm{HNCHCH}_{2} \mathrm{OH}+\mathrm{HO}_{2}$ & $1.2 \times 10^{-19}$ & Nielsen et al. (2010) ${ }^{\mathrm{d}}$ \\
\hline 14 & $\mathrm{MEAN}+\mathrm{NO}$ & $\rightarrow$ & MEANNO & $8.5 \times 10^{-14}$ & Nielsen et al. $(2010)^{\mathrm{d}}$ \\
\hline 15 & MEANNO2 + OH & $\rightarrow$ & $\mathrm{MEANHA}+\mathrm{HO}_{2}$ & $1.48 \times 10^{-11}$ & EPI Suite ${ }^{\mathrm{TM}} \mathrm{v} 4.0$ \\
\hline 16 & $\mathrm{HNCHCH}_{2} \mathrm{OH}+\mathrm{OH}$ & $\rightarrow$ & $\mathrm{H}_{2} \mathrm{NCOCH}_{2} \mathrm{OH}+\mathrm{HO}_{2}$ & $3.0 \times 10^{-13}$ & EPI Suite ${ }^{\mathrm{TM}} \mathrm{v} 4.0$ \\
\hline 17 & MEANNO + hv & $\rightarrow$ & MEAN + NO & $j=0.33 * j\left(\mathrm{NO}_{2}\right)$ & This work, estimate \\
\hline
\end{tabular}

${ }^{a}$ List of model surrogate compounds and compounds with shortname: MEAN: N-amino ethanol radical, MEABO2: C2-amine peroxy radical, MEABO: C2-amine alkoxy radical, MEANNO: 2-(N-nitrosoamino)-ethanol, MEANNO2: 2-nitroamino ethanol, MEANHA: N-nitro hydroxyacetamide, MMAO2: methylamine peroxy radical. b Rate constant in units $\mathrm{cm}^{3}$ molecule $\mathrm{s}^{-1}$ for bimolecular reactions. ${ }^{\mathrm{c}}$ Generic rate constant adopted from the Master Chemical Mechanism (MCM) v3.1 (Bloss et al., 2005b), available at http://mcm.leeds.ac.uk/MCMv3.1. ${ }^{\mathrm{d}}$ Rate constant estimated based on analogous dimethylamine reactions.

amino acetaldehyde $\left(\mathrm{H}_{2} \mathrm{NCH}_{2} \mathrm{CHO}\right)$, 2-oxo-acetamide $\left(\mathrm{H}_{2} \mathrm{NC}(\mathrm{O}) \mathrm{CHO}\right)$, 2-imino ethanol $\left(\mathrm{HN}=\mathrm{CHCH}_{2} \mathrm{OH}\right)$ and the 2-nitroamino ethanol (for more details it is referred to Table 1 in the publication by Nielsen et al., 2011). The $\mathrm{OH}+\mathrm{MEA}$ mechanism presented in Table 3 includes reaction pathways leading to the formation of all these compounds. In addition to the schematic gas phase degra- dation routes outlined by Nielsen et al. (2011), kinetic and mechanistic information about the degradation of the major oxidation product, i.e. formamide, provided by Barnes et al. (2010) was taken into account. Average branching ratios of the initial $\mathrm{H}$-abstraction given by Nielsen et al. (2011) are $8 \%$ from $-\mathrm{NH}_{2}, 84 \%$ from $-\mathrm{CH}_{2}-$ and $8 \%$ from $-\mathrm{CH}_{2} \mathrm{OH}$. In our presented mechanism, the branching ratios 
were slightly modified and are $15 \%, 80 \%$, and $5 \%$ for the $-\mathrm{NH}_{2},-\mathrm{CH}_{2}-$, and $-\mathrm{CH}_{2} \mathrm{OH}$ positions, respectively. These branching ratios have been used in model simulations of EUPHORE experiments in the report by Nielsen et al. (2010) and resulting gas phase concentrations of formamide and 2-nitroamino ethanol were in agreement with measured concentrations of these compounds by PTR-TOF-MS within the uncertainty of measured data.

EPI Suite ${ }^{\mathrm{TM}}$ version 4.0 (US EPA, 2009) has been used to estimate rate constant for reactions with the $\mathrm{OH}$ radical in case no experimental data was available. The Atkinson method is implemented in the program EPI Suite ${ }^{T M}$ through the module AOPWIN. AOPWIN incorporates updated fragment and reaction values as given by Kwok and Atkinson (1995). In addition, Syracuse Research Corporation has added additional fragment and reaction values from more recent experimental data (Meylan and Howard, 2000). The accuracy of the method has been evaluated in a test of 720 chemicals with respect to the non-logarithmic rate constant values: $90 \%$ of the predicted values were within a factor 2 of experimental data and $95 \%$ within a factor 3 (Meylan and Howard, 2003). Unfortunately, Atkinson's method has shown larger deviations for several important classes of chemical compounds such as organic compounds with 3 halogens on the same carbon atom (as in DDT), chemicals with $\mathrm{NO}_{\mathrm{x}}$-groups as in nitroalkanes, phosphates, often used in herbicides, and small heterocyclic rings (Güsten, 1999).

\subsection{SOA formation in the $\mathrm{OH}$-initiated oxidation of MEA}

MAFOR uses a hybrid method of condensation and partitioning to treat formation of SOA from the $\mathrm{OH}$-initiated oxidation of MEA. Currently, very little is known about individual SOA compounds that form in the photo-oxidation of MEA (Nielsen et al., 2011). Therefore the simplified approach of a one-product model was chosen to represent SOA from $\mathrm{OH}$ initiated MEA oxidation. The clear advantage of the oneproduct SOA model over a two-product model (Odum et al., $1996,1997)$ is the need for fewer parameters. The single SOA product, termed MEAp1, is formed in the initial reaction of MEA and $\mathrm{OH}$ (Reaction R1b below) with the molar stoichiometric yield $\alpha_{1}$ (see Table 4):

$$
\begin{aligned}
& \mathrm{H}_{2} \mathrm{NCH}_{2} \mathrm{CH}_{2} \mathrm{OH}+\mathrm{OH} \stackrel{k_{1}}{\longrightarrow} \\
&\left(1-\alpha_{1}\right) \text { gas phase products (R1a) } \\
& \mathrm{H}_{2} \mathrm{NCH}_{2} \mathrm{CH}_{2} \mathrm{OH}+\mathrm{OH} \stackrel{k_{1}}{\longrightarrow} \alpha_{1} \mathrm{MEAp} 1 \quad \text { (R1b) }
\end{aligned}
$$

The equilibrium partitioning of the condensable compound between the gas phase and the aerosol phase is described by the gas/particle partitioning coefficient for absorptive uptake into the particle phase (e.g. Seinfeld and Pankow, 2003). An ideal solution was assumed between the dissolved species (MEAp1), and the other components of the particulate phase.
Table 4. Parameters of the one-product model for $\mathrm{SOA}^{\mathrm{a}}$ formed in reaction $\mathrm{OH}+\mathrm{MEA}$.

\begin{tabular}{lllll}
\hline SOA product & $\begin{array}{l}\alpha \\
\left(\text { mass-based }^{\mathrm{b}}\right)\end{array}$ & $\begin{array}{l}p_{L}^{0} \\
(\mathrm{~Pa} \text { at } 296 \mathrm{~K})\end{array}$ & $\begin{array}{l}\Delta H_{\mathrm{vap}} \\
\left(\mathrm{kJmol}^{-1}\right)\end{array}$ & $\begin{array}{l}\mathrm{MW} \\
\left(\mathrm{gmol}^{-1}\right)\end{array}$ \\
\hline MEAp1 & $0.80 \pm 0.04$ & $3.9 \times 10^{-5 \mathrm{c}}$ & $138^{\mathrm{c}}$ & 126 \\
\hline
\end{tabular}

a The SOA yield $Y^{\mathrm{SOA}}$ can be expressed as a function of $\Delta M_{\mathrm{O}}$ by (Odum et al., 1996):

$Y^{\mathrm{SOA}}=\Delta M_{\mathrm{O}} \sum_{i} \frac{\alpha_{i} K_{\mathrm{om}, i}}{1+K_{\mathrm{om}, i} \Delta M_{\mathrm{O}}}$

where $K_{\mathrm{Om}, i}$ of a SOA compound $i$ is defined as $K_{\mathrm{Om}, i}=K_{p, i}^{\mathrm{SOA}} / f$, with and $f$ being the absorptive mass fraction. The gas phase/particle partitioning coefficient, $K_{p, i}^{\mathrm{SOA}}$, is calculated according to:

$K_{p, i}^{\mathrm{SOA}}=\frac{10^{-6} R T f}{\mathrm{MW} \zeta_{i} p_{L, i}^{0}}$

where the activity coefficient $\zeta_{i}$ is unity, and $R$ is the universal gas constant $\left(8.206 \times 10^{-5} \mathrm{~m}^{3} \mathrm{~atm} \mathrm{~mol}^{-1} \mathrm{~K}^{-1}\right)$.

b Mass-based stoichiometric yield $\alpha_{1}$ was determined from fit to experimental data assuming a one-product model using a modified Marquardt-Levenberg parameter estimation method (Fahlman, 2001). Given errors are statistical errors of the measurements of $M_{\mathrm{O}}$ and MEA. Fitting the experimental data with a two-product model resulted $\alpha_{1}=0.76 \pm 0.04$ and $\alpha_{2}=0.09 \pm 0.01$; the vapour pressure of the second SOA product was assumed to be a factor of 100 lower than that of MEAp1.

c Vapour pressure $\left(p_{L}^{0}\right)$ and enthalpy of vaporization $\left(\Delta H_{\mathrm{vap}}\right)$ of succinic acid, adopted from Bilde et al. (2003).

The SOA yield from $\mathrm{OH}$-initiated oxidation was determined in experiments E4 and E5 (Table 1) as the ratio of the amount of MEA reacted $\left(\triangle \mathrm{MEA}_{\text {reac }}\right)$ to the total mass concentration of organic aerosol $\left(\Delta M_{\mathrm{O}}\right)$. The time series of reacted $\triangle \mathrm{MEA}_{\text {reac }}$ was derived from a model simulation with MAFOR and time synchronized to the time series of $\Delta M_{\mathrm{O}}$ measured by AMS. SOA yields, $Y^{\mathrm{SOA}}$, were calculated for each AMS data point in E4 and for the final AMS data point in $\mathrm{E} 5\left(Y^{\mathrm{SOA}}=\Delta M_{\mathrm{O}} / \Delta \mathrm{MEA}_{\text {reac }}\right)$. Mass-based stoichiometric yields for MEA were fit to the experimental yield data by using a modified Marquardt-Levenberg parameter estimation method (Fahlman, 2001). Parameters resulting from the fit to the yield curve (Fig. 2) are provided in Table 4.

The finding that the one-product was sufficient to explain the data indicates that the vapor pressures of the SOA compounds are very similar or that only a very small fraction of a less volatile product is formed. A two-product model was also tested but did not result in a better fit to the data. It is noted that gas phase loss of MEAp1 to the chamber walls was not considered in this study.

In the photo-oxidation of 1,3,5-trimethylbenzene massbased aerosol yields ranging from 3.4 to $8.1 \%$ have been found in experiments without seed particles present (Cocker et al., 2001). Based on this a molar-based SOA yield of $4 \%$ in the reaction of $\mathrm{OH}$ with TMB was assumed in the model calculations of this study. 


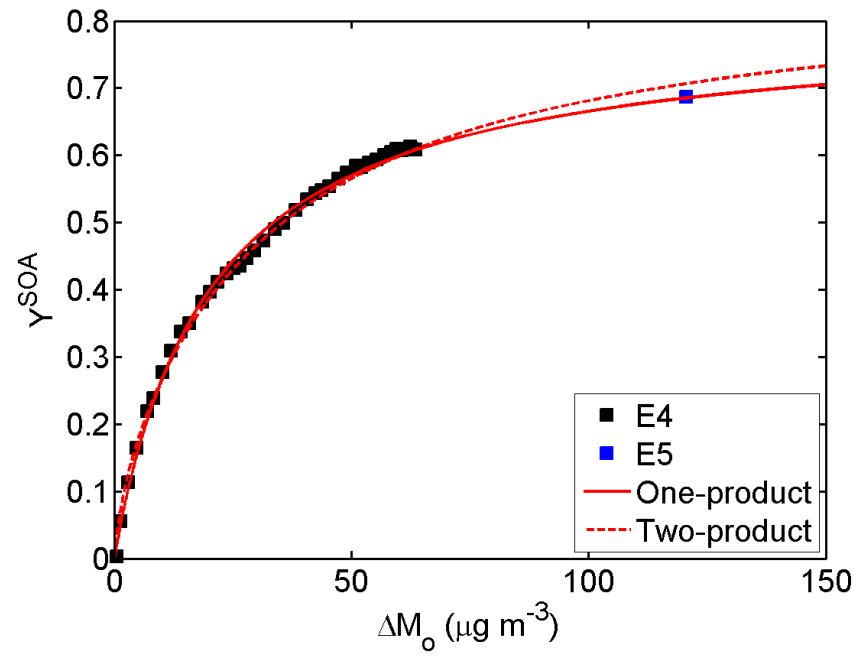

Fig. 2. Secondary organic aerosol yields in the $\mathrm{OH}$-initiated oxidation of MEA as function of organic mass concentration (measured by AMS) in experiment E4 and E5. Data are shown as filled squares. Curves were fitted to the data using the one-product model (solid line) and the two-product model (dashed line). Parameters obtained from the fit are given in Table 4 .

\subsection{MEA losses to particles}

The mass balance of MEA considering losses through Reactions (R1)-(R4):

$$
\frac{d[\mathrm{MEA}]}{\mathrm{d} t}=L_{\mathrm{MEA}}+\left(\frac{d[\mathrm{MEA}]}{\mathrm{d} t}\right)_{\text {particles }}+\left(\frac{d[\mathrm{MEA}]}{\mathrm{d} t}\right)_{\rho}
$$

Here the squared brackets denote gas phase concentrations (in molecules $\mathrm{cm}^{-3}$ ). The first term on the right hand side (RHS) of Eq. (1), $L_{\mathrm{MEA}}$, is the total gas phase pseudo first order loss rate:

$$
L_{\mathrm{MEA}}=-\left(k_{1}[\mathrm{OH}]+k_{\mathrm{dil}}+k_{\mathrm{wall}}\right)[\mathrm{MEA}]
$$

The second term on the right hand side of Eq. (1) accounts for concentration changes due to formation of amine salts that partition to the aerosol phase and the third term considers concentration changes due to changes of density of air, $\rho$, caused by the daily cycle of pressure and temperature. MEA concentration changes with time due to transfer to/from particles are predicted by:

$$
\begin{aligned}
\left(\frac{d[\mathrm{MEA}]}{\mathrm{d} t}\right)_{\text {particles }}= & -2 \pi D \sum_{k=1}^{N_{\mathrm{B}}} N_{k} d_{p, k} f\left(K n, \alpha_{\mathrm{m}}\right) \\
& \times\left([\mathrm{MEA}]-[\mathrm{MEA}]^{\mathrm{eq}}\right) \\
& -J_{\text {nucl }} v_{\text {MEA }}
\end{aligned}
$$

The first term on RHS of Eq. (3), describes concentration changes due to mass transfer of the ethanolaminium nitrate produced in Reaction (R4) to a particle population. The second term on RHS considers loss of MEA due to nucleation of
MEA- $\mathrm{HNO}_{3}$ clusters. In Eq. (3), $N_{k}$ is the number concentration of particles in size bin $k$, (with $N_{\mathrm{B}}$ being the number of size bins), $f\left(K n, \alpha_{\mathrm{m}}\right)$ is the correction for non-continuum effects and imperfect accommodation as defined by Fuchs and Sutugin (1970), $K n$ is the Knudsen number, $D$ is the gas phase diffusion coefficient, $d_{p, k}$ the diameter of particles in size bin $k, v_{\mathrm{MEA}}$ is the volume ratio (ratio of the volume of a MEA molecule to the volume of a particle in the first size bin). The accommodation coefficient $\alpha_{\mathrm{m}}$ for the mass transfer of ethanolaminium nitrate to particles was assumed to equal unity.

The equilibrium concentration of MEA, $[\mathrm{MEA}]^{\mathrm{eq}}$, in the $\mathrm{MEA}-\mathrm{HNO}_{3}$ system is defined in analogy to the ammonia-nitric acid system, by (Seinfeld and Pandis, 1998):

$$
\begin{aligned}
{[\mathrm{MEA}]^{\mathrm{eq}}=} & \left(\frac{[\mathrm{MEA}]+\left[\mathrm{HNO}_{3}\right]}{2}\right) \\
& +\sqrt{\frac{\left([\mathrm{MEA}]-\left[\mathrm{HNO}_{3}\right]\right)^{2}}{4}+K_{p}^{\prime}}
\end{aligned}
$$

The dissociation constant, $K_{p}^{\prime}$ in units (molecules $\left.\mathrm{cm}^{-3}\right)^{2}$, for ethanolaminium nitrate can be defined as product of the equilibrium concentrations of MEA and $\mathrm{HNO}_{3}$ (Seinfeld and Pandis, 1998):

$$
K_{p}^{\prime}=K_{p} /(\mathrm{RT})^{2}=[\mathrm{MEA}]^{\mathrm{eq}} \times\left[\mathrm{HNO}_{3}\right]^{\mathrm{eq}}
$$

Formation of the ethanolaminium nitrate salt according to (R4) is limited by the availability of the least abundant of the two species. Any excess of MEA may then react with $\mathrm{HNO}_{3}$ to form the ethanolaminium nitrate. Ge et al. (2011b) estimated dissociation constants of several aminium nitrate salts in the temperature range $263.15-323.15 \mathrm{~K}$. The dissociation constant of ethanolaminium nitrate is given by $K_{p}^{\prime}=8 \times 10^{16}$ (molecules $\left.\mathrm{cm}^{-3}\right)^{2}$ at $293.15 \mathrm{~K}$ (Ge et al., 2011b) and this value was used for the modelling of the experiments in our study.

It is assumed in this work that nucleation observed in MEA oxidation experiments occurs through homogenous heteromolecular nucleation between $\mathrm{HNO}_{3}$ and MEA vapour molecules, or one of the vapours activating the clusters composed around a molecule of the other vapour. The parameterization for the nucleation process developed in this work is:

$$
\begin{array}{ll}
J_{\text {nucl }}=K_{\text {nucl }}[\mathrm{MEA}] \times\left[\mathrm{HNO}_{3}\right] & {[\mathrm{MEA}] \times\left[\mathrm{HNO}_{3}\right]>K_{p}^{\prime}} \\
J_{\text {nucl }}=0 & {[\mathrm{MEA}] \times\left[\mathrm{HNO}_{3}\right] \leq K_{p}^{\prime}}
\end{array}
$$

According to this parameterization, nucleation can only happen when the product of $\mathrm{HNO}_{3}$ and MEA concentrations exceeds a threshold of $K_{p}^{\prime}$. $\quad K_{\text {nucl }}$ is an empiric nucleation parameter. An average nucleation parameter is given by $K_{\text {nucl }}=2 \times 10^{-20} \mathrm{~cm}^{3}$ molecules ${ }^{-1} \mathrm{~s}^{-1}$, as determined by fitting the temporal evolution of number size distributions during MEA experiments in EUPHORE (Nielsen et al., 2010), and was used for the modelling of the experiments in our study. 


\subsection{Model simulation of chamber experiments}

The loss of MEA to the aerosol phase in the experiments competes with the gas phase reaction between $\mathrm{OH}$ and MEA. For the determination of the rate constant between $\mathrm{OH}$ and MEA in this work an estimate of the net loss rate of MEA to particles is required. To this end, Eq. (3) is expressed as net loss of MEA to the aerosol phase of the form:

$$
\left(\frac{d[\mathrm{MEA}]}{\mathrm{d} t}\right)_{\text {particles }}=-k_{\text {particles }}[\mathrm{MEA}]
$$

with

$$
\begin{aligned}
k_{\text {particles }}= & 2 \pi D \sum_{k=1}^{N_{\mathrm{B}}} N_{k} d_{p, k} f\left(K n, \alpha_{\mathrm{m}}\right) \times\left(1-\frac{\left.{[\mathrm{MEA}]^{\mathrm{eq}}}_{[\mathrm{MEA}]}\right)}{}+J_{\text {nucl }} v_{\mathrm{MEA}}[\mathrm{MEA}]^{-1}\right.
\end{aligned}
$$

where $k_{\text {particles }}$ is a quasi first order loss rate constant. Since $k_{\text {particles }}$ depends on the actual MEA equilibrium concentration (see Eq. 4), it is not possible to determine it directly from measured concentrations of particle numbers. MAFOR is used in this study to compute $k_{\text {particles }}$ as function of time in each experiment. The model included the atmospheric mechanism of $\mathrm{OH}+\mathrm{MEA}$ (Sect. 3.3); the oneproduct model for SOA formation (Sect. 3.4) and the formation of ethanolaminium nitrate salt (Sect. 3.5). Gas phase concentrations of $\mathrm{HONO}$ and $\mathrm{HNO}_{3}$ were not monitored in the chamber experiments. However, FT-IR signal indicates that $\mathrm{HNO}_{3}$ concentrations were below the detection limit of 2 ppbv during the experiments. In the model calculations, the only adjusted parameters are the start concentration of HONO and the chamber wall source of HONO, which affect both the $\mathrm{OH}$ concentration and $\mathrm{NO}_{\mathrm{x}}$ available for the formation of the ethanolaminium nitrate salt. A factor $F_{\text {source }}$ was used to scale the chamber wall source of $\mathrm{HONO}\left(S_{\mathrm{HONO}}\right)$ :

$S_{\mathrm{HONO}}^{\mathrm{fit}}=F_{\text {source }} \times S_{\mathrm{HONO}}$

The fit procedure proceeded until best agreement between modelled and monitored time series of total and nitrate particle mass concentrations (as measured by AMS) and of MEA gas phase concentrations as well as of TMB gas phase concentrations (in case TMB was present) had been achieved. Comparison of AMS nitrate signals obtained during the experiments with the nitrate signal of the pure ethanolaminium nitrate (reference) salt revealed that about $85 \%$ of the total nitrate concentrations observed in the experiments of this study could be attributed to ethanolaminium nitrate salt.

\section{Relative rate}

For the chamber experiments, the balance equations of MEA, $\mathrm{TMB}$ and $\mathrm{SF}_{6}$ can be written as a set of first order ordinary differential equations:

$$
\begin{aligned}
\left(\frac{d<\mathrm{MEA}>}{\mathrm{d} t}\right)= & -\left(k_{1}[\mathrm{OH}]+k_{\mathrm{dil}}+k_{\mathrm{wall}}+k_{\text {particles }}\right) \\
& <\mathrm{MEA}> \\
\left(\frac{d<\mathrm{TMB}>}{\mathrm{d} t}\right)= & -\left(k_{\mathrm{ref}}[\mathrm{OH}]+k_{\mathrm{dil}}\right)<\mathrm{TMB}> \\
\left(\frac{d<\mathrm{SF}_{6}>}{\mathrm{d} t}\right)= & -k_{\mathrm{dil}}<\mathrm{SF}_{6}>
\end{aligned}
$$

We note that the density dependent term vanishes when mixing ratio (denoted by $<>$ ) is used instead of concentration. After integration and rearrangement of the set of balance equations, see Eqs. (A1)-(A10) in the Appendix A, it is possible to derive a standard relative rate equation:

$Y_{\mathrm{MEA}}^{\prime}(t)=\frac{k_{1}}{k_{\mathrm{ref}}} X_{\mathrm{TMB}}^{\prime}(t)$

A linear least-squares-model (LSQ) is invoked by

$Y_{\mathrm{MEA}}^{\prime}(t)=a+b \cdot X_{\mathrm{TMB}}^{\prime}(t)$

where the slope $b$ corresponds to the ratio $k_{1} / k_{\text {ref }}$ and $a$ is the offset from zero of the $y$-axis. The reference rate constant $k_{\text {ref }}$ for the $\mathrm{OH}+\mathrm{TMB}$ reaction is taken from Aschmann et al. (2006), with the temperature dependent expression: $k_{\text {ref }}(T)=4.40 \times 10^{-12} \exp (738 \pm 176 / T)$.

\section{Results}

The time series for the pseudo first order loss processes were time synchronized onto the HT-PTR-MS time grid before use in the LSQ model. Only the first 1300 s of the respective sunlit experiment were analyzed with the LSQ model. For each experiment, the first order loss rate constants and their associated uncertainties were determined (average and standard deviation in Table 5). The time-dependent dilution loss term $D_{\mathrm{SF}_{6}}(t)$ (defined by Eq. A6) was derived from the measured $\mathrm{SF}_{6}$ time series. The time-dependent loss rate of MEA to particles, $k_{\text {particles}}$, was determined by the chamber aerosol model according to Eq. (7), as described in Sect. 3.6. Modelled time series of total aerosol mass concentrations obtained in the fit procedure are in excellent agreement with the total mass concentration measured by AMS (Fig. 3).

The lifetime of MEA towards dilution, wall loss and loss to particles ranged between 8-11 h, 1-2 h and 40-60 h, respectively. Thus, loss of MEA to particles was the least sensitive parameter in the LSQ for determination of the rate constant $k_{1}$.

Linear regression which takes into account errors in both $X^{\prime}$ and $Y^{\prime}$ was applied and a regression routine based on FITEXY.C (Press et al., 1992) was used. This regression method usually provides a better estimate of the true value of the slope $\left(k_{1} / k_{\text {ref }}\right)$ and of the intercept than a simple regression analysis which does not take the errors of the measured concentrations of both reactants into account (Brauers 

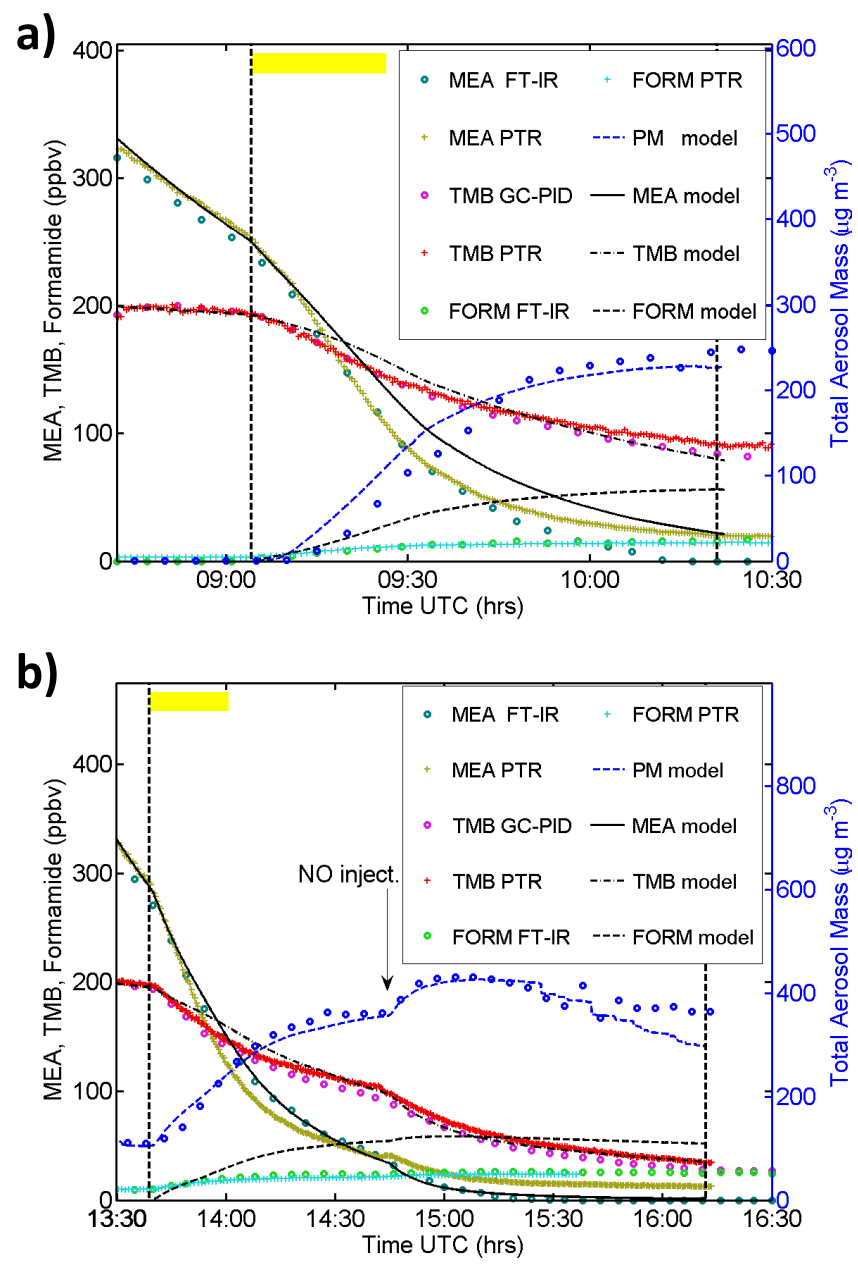

Fig. 3. Measured and modelled time series of MEA, TMB and formamide mixing ratios in (a) experiment $\mathrm{E} 1$ and (b) experiment E2. MEA measurements (golden crosses) from HT-PTR-MS are partly overlaying the MEA data from FT-IR (dark green circles). Measured (blue circles) and modelled (blue dashed line) total aerosol mass concentrations (PM) are in good agreement. Vertical dashed lines indicate beginning and end of the sunlit experiment. Rate constant $k_{1}$ was scaled by a factor of 2.6 in the model simulations. Horizontal bar (yellow) marks the time period of the experiment used for the relative rate determination using the LSQ model.

and Finlayson-Pitts, 1997). Results of the LSQ for experiment E1 and E2 are shown in Fig. 4 and the corresponding values for $a$ and $b$ are given in Table 6. $X^{\prime}$ and $Y^{\prime}$ were found to be highly correlated, correlation coefficients were $R^{2}=0.981$ in $\mathrm{E} 1$ and $R^{2}=0.992$ in E2. The merit function $\chi^{2}$ provides a means for the "goodness of fit" of the data to the invoked linear model (Press et al., 1992). In both experiments the probability that $\chi^{2}$ exceeds a particular value by chance was $Q=1$ in the regression analysis, supporting the adequateness of the linear LSQ model.

Further the validity of the LSQ model was tested in Monte Carlo (MC) simulations where the time series $X^{\prime}(\mathrm{TMB}, t)$
Table 5. Loss rates in Experiment E1 and E2. Particle loss given as model average particle loss rate (according to Eq. 7) in the first half hour of the sunlit experiment..

\begin{tabular}{lccc}
\hline Experiment & $\begin{array}{c}k_{\text {dil }}{ }^{\mathrm{a}} \\
\left(\mathrm{s}^{-1}\right)\end{array}$ & $\begin{array}{c}k_{\text {wall }}{ }^{\mathrm{a}} \\
\left(\mathrm{s}^{-1}\right)\end{array}$ & $\begin{array}{c}k_{\text {particles }} \\
\left(\mathrm{s}^{-1}\right)\end{array}$ \\
\hline E1 & $(2.45 \pm 0.74) \times 10^{-5}$ & $(1.86 \pm 0.65) \times 10^{-4}$ & $(7.0 \pm 2.7) \times 10^{-6}$ \\
E2 & $(3.12 \pm 0.34) \times 10^{-5}$ & $(2.32 \pm 0.86) \times 10^{-4}$ & $(4.8 \pm 0.5) \times 10^{-6}$ \\
\hline
\end{tabular}

a $1-\sigma$ variance from least square fit weighted by measurement uncertainties. ${ }^{\mathrm{b}}$ Standard deviation of the average modelled particle loss rate.

and $Y^{\prime}$ (MEA, $t$ ) were shifted randomly according to the standard deviation of the MEA and TMB measurements and of the loss terms (with $M=10000$ repetitions). It is noted that the values of $a$ and $b$ and their variance (1- $\sigma$ standard deviation of the mean) resulting from MC analysis were not significantly different from the values obtained in the LSQ fit.

An alternative way of estimating the standard errors of the LSQ parameters is to perform bootstrap analysis, i.e. estimating the variability of a statistic from the data set by re-sampling it independently and with equal probabilities (MC re-sampling). A bootstrap Model II procedure should be used when the two variables in the regression equation are random and subject to error. Bootstrap Reduced Major Axis Regression was applied with 1000 re-samplings, 50 blocks and at a significance level of 0.05 ; resulting LSQ parameters (E1: $a=-0.05 \pm 0.01$, $b=1.93 \pm 0.04$; E2: $a=-0.04 \pm 0.01, b=1.71 \pm 0.02$ ) were in agreement with the regression using FITEXY, the standard errors were however smaller. It is noted that the applied bootstrap method is non-parametric and thus does not assume explicit error propagation.

A slight curvature of the data can however be noted in Fig. 4 for the data points in both experiments. During the first $3-5 \mathrm{~min}$ of the relative rate experiment, data points seem to follow the unity slope (grey dashed 1:1 line) while the later data points are all on a line with a slope greater than unity as it is indicated by the LSQ model. A reason for the obvious curvature could be that the loss processes other than $\mathrm{OH}$-reaction were not correctly subtracted when calculating $Y^{\prime}$ (Eq. 9) or that these loss processes are time-dependent. When a longer time period of the experiments, for instance $2600 \mathrm{~s}$, is considered, the LSQ model resulted a slope $>2$. This could indicate that there is a loss process that increases over time during the sunlit experiment. While the timedependence of the dilution loss and the particle loss terms can be accurately estimated, the time behaviour of the wall loss term is unknown. A more detailed discussion of the wall loss follows in Sect. 6.1.

Based on the results from the LSQ model, the rate constant $k_{1}$ of the reaction between $\mathrm{OH}$ and MEA is found to be $(9.3 \pm 1.0) \times 10^{-11} \mathrm{~cm}^{3}$ molecule ${ }^{-1} \mathrm{~s}^{-1}$ in experiment $\mathrm{E} 1$ (average temp. $303.6 \pm 0.4 \mathrm{~K}$ ) and 
Table 6. Rate constant $k(\mathrm{OH}+\mathrm{MEA})$ values estimated by SAR and as determined in Experiment E1 and E2. LSQ parameters and their uncertainties are provided for the experimentally derived rate constant values.

\begin{tabular}{|c|c|c|c|c|c|}
\hline \multirow{2}{*}{ Method } & \multirow{2}{*}{$\begin{array}{l}k(\mathrm{OH}+\mathrm{MEA}) \\
\left(\mathrm{cm}^{3} \text { molecule }^{-1} \mathrm{~s}^{-1}\right)\end{array}$} & \multirow{2}{*}{$\begin{array}{l}\text { Temp. } \\
(\mathrm{K})\end{array}$} & \multicolumn{2}{|c|}{ LSQ parameters } & \multirow[t]{2}{*}{ Reference } \\
\hline & & & $a$ & $b^{\mathrm{a}}$ & \\
\hline SAR Estimate & $3.58 \times 10^{-11}$ & 298.25 & & & EPI Suite ${ }^{\mathrm{TM}} \mathrm{v} 4.0$ \\
\hline SAR Estimate & $4.41 \times 10^{-11}$ & 300.0 & & & Carter (2008) \\
\hline E1, LSQ & $(9.3 \pm 1.0) \times 10^{-11}$ & $303.6 \pm 0.4$ & $-0.04 \pm 0.01$ & $1.86 \pm 0.08$ & This work \\
\hline E2, LSQ & $(8.1 \pm 0.8) \times 10^{-11}$ & $306.6 \pm 1.4$ & $-0.03 \pm 0.02$ & $1.65 \pm 0.07$ & This work \\
\hline
\end{tabular}

${ }^{\text {a }}$ It is $b=k / k_{\text {ref }}$, where $k_{\text {ref }}$ is the rate constant of the $\mathrm{OH}+\mathrm{TMB}$ reaction taken from Aschmann et al. (2006). The value of $k_{\text {ref }}$ is calculated to be $5.02 \times 10^{-11} \mathrm{~cm}^{3}$ molecule ${ }^{-1} \mathrm{~s}^{-1}$ in $\mathrm{E} 1$ and $4.89 \times 10^{-11} \mathrm{~cm}^{3}$ molecule $\mathrm{e}^{-1} \mathrm{~s}^{-1}$ in $\mathrm{E} 2$.

$(8.1 \pm 0.8) \times 10^{-11} \mathrm{~cm}^{3}$ molecule $\mathrm{e}^{-1} \mathrm{~s}^{-1} \quad$ in $\quad$ E2 (average temperature $306.6 \pm 1.4 \mathrm{~K}$ ). The average rate constant from the two experiments, extrapolated to $298 \mathrm{~K}$ using the temperature dependence of $k_{\text {ref }}$, is $(9.2 \pm 1.1) \times 10^{-11} \mathrm{~cm}^{3}$ molecule $\mathrm{s}^{-1} \mathrm{~s}^{-1}$. This experimentally derived value is a factor of 2.6 higher than the value of $3.58 \times 10^{-11} \mathrm{~cm}^{3}$ molecule ${ }^{-1} \mathrm{~s}^{-1}$ predicted by EPI Suite v4.0 which makes use of the Atkinson SAR (Table 6).

With the intention to study the sensitivity of the coupled gas-phase/aerosol chemistry system on sudden changes of the $\mathrm{VOC} / \mathrm{NO}_{\mathrm{x}}$ regime, experiment $\mathrm{E} 2$ was perturbed by the injection of $12 \mathrm{ml} \mathrm{NO}$ at 14:42 UTC, about $1 \mathrm{~h}$ after opening the canopy (Fig. 1b). The primary effect of the NO injection was to increase ozone production (ozone mixing ratio increased by $40 \mathrm{ppbv}$ ) and by this to increase $\mathrm{OH}$-reactivity, causing pronounced changes of measured decay rates of MEA and TMB (HT-PTR-MS data, Fig. 3b). The secondary effect was to increase production of gaseous $\mathrm{HNO}_{3}$ through the $\mathrm{OH}+\mathrm{NO}_{2}$ reaction potentially causing more particlebound nitrate to be formed. The total aerosol mass concentration increased by $70 \mu \mathrm{g} \mathrm{m}^{-3}$. According to the simulation with MAFOR, the observed aerosol mass increase was mainly due to increase of nitrate. MAFOR predicts slightly faster MEA decay compared to HT-PTR-MS.

In further simulations with MAFOR the effect of the higher $k(\mathrm{OH}+\mathrm{MEA})$ value found in this work on the predicted concentrations of gaseous oxidation products was investigated. Experiment E3 was modelled in the same way as described in Sect. 3.6, by scaling the rate constant value of $k_{1}=3.58 \times 10^{-11} \mathrm{~cm}^{3}$ molecule ${ }^{-1} \mathrm{~s}^{-1}$ by a factor of 2.6, and fitting the model output towards measured MEA mixing ratios and aerosol mass concentrations (Fig. 5).

Modelled formamide mixing ratios were found to agree very well with those measured by FT-IR, while overestimating those measured by PTR-TOF-MS. By repeating the simulation with the original value of $k_{1}$ and comparing the modelled time series, it was found that steady state concentrations of 2-nitroamino ethanol and formamide in the experiment increased by $39 \%$ and $36 \%$, respectively, when applying the higher $k_{1}$ value.
MAFOR predicted 2-nitroamino ethanol concentrations of up to 3 ppbv in experiment E3. Based on the model results, the product yield of the nitramine was estimated to be $0.75 \%$, which is within the range of experimental product yields of $0.3 \%$ to $1.5 \%$ found by Nielsen et al. (2011) in experiments with various $\mathrm{NO}_{\mathrm{x}}$-levels. Measured concentrations of 2-nitroamino ethanol obtained from the onlinemethod PTR-TOF-MS and from the offline analysis of ThermosorbN cartridges using liquid chromatography were however lower than the modelled concentrations by a factor of $40-50$ and by a factor of $5-10$, respectively (see Table 7). Despite the discrepancy between the two employed methods, measured concentrations of 2-nitroamino ethanol indicate that the model overestimates the production yield of the nitramine by at least a factor of 5. It is noted that both online and offline detection methods for the measurement of nitramines have been largely improved since the report by Nielsen et al. (2010).

The nitrosamine of MEA; 2-nitroso amino ethanol, was not detected in the experiments with any of the methods, in line with the findings by Nielsen et al. (2011). Our mechanism (Table 3) predicts the formation of the nitrosamine with a very small yield and its rapid destruction by photolysis. Theoretical studies (Angove et al., 2010) suggest that 2-nitroso amino ethanol partly undergoes immediate isomerisation to 2-hydroxydiazenyl ethanol $\left(\mathrm{HOCH}_{2} \mathrm{CH}_{2} \mathrm{~N}=\mathrm{NOH}\right)$ which then decomposes to give 2-imino ethanol.

\section{Discussion}

\subsection{Rate constant uncertainties}

It was assumed that the wall loss rate of MEA was the same in the sunlit experiment as in the dark period before opening the canopy. During the experiment, the chamber walls are heated by the sun which could cause desorption of MEA from the Teflon surface, leading to smaller wall loss rates. On the contrary, heating of the chamber floor by the sun may cause convective movement of air inside the chamber which 
Table 7. Measured and modelled mixing ratios (pptv) of 2-nitroamino ethanol in experiment E3 as averages for certain sampling periods before and during the sunlit experiment. Modelled concentrations are shown using the rate constant $k(\mathrm{OH}+\mathrm{MEA})$ value 1$)$ estimated by EPI SuiteTM v4.0 and 2) obtained in this work.

\begin{tabular}{|c|c|c|c|c|c|}
\hline \multirow{2}{*}{$\begin{array}{l}\text { Sample } \\
\text { no. }\end{array}$} & \multirow{2}{*}{$\begin{array}{c}\text { Sampling } \\
\text { period (UT) }\end{array}$} & \multirow{2}{*}{$\begin{array}{l}\text { PTR-TOF-MS } \\
\text { average (pptv) }\end{array}$} & \multirow{2}{*}{$\begin{array}{r}\text { HPLC-HRMS } \\
\text { ThermosorbN } \\
\text { (pptv) }\end{array}$} & \multicolumn{2}{|c|}{ Model average (pptv) } \\
\hline & & & & $\begin{array}{r}k_{1} \\
\text { (EPI Suite) }\end{array}$ & $\begin{array}{r}k_{1} \\
\text { (This work) }\end{array}$ \\
\hline $\mathrm{E} 3-1^{\mathrm{a}}$ & $10: 36-11: 42$ & 0.6 & 8 & 0 & 0 \\
\hline E3-2 & $11: 55-12: 56$ & 21 & 193 & 1045 & 1240 \\
\hline E3-3 & $13: 22-14: 11$ & 44 & 210 & 2018 & 2692 \\
\hline E3-4 & $14: 24-15: 19$ & 55 & 217 & 2122 & 2953 \\
\hline
\end{tabular}

a Taken before start of the sunlit experiment.

would cause a more rapid loss of MEA to the Teflon walls. As noted before, the curvature of the relative rate data indicates a loss rate that increases over time during the sunlit experiment. It can be speculated that the temperature of the floor increased during the sunlit experiment (despite the floor cooling) and consequently accelerated the convective movement. However, we note that mixing of the chamber air by the powerful fan system $\left(67 \mathrm{~m}^{3} \mathrm{~min}^{-1}\right.$ air throughput running throughout the experiment) will introduce a much stronger movement of air than the thermally induced convection does. Mixing by the fans is expected to result in a constant loss of MEA to the Teflon walls.

We assume that there was a high short-term variability after the opening of the chamber canopy which introduced large errors to the first measured data points of the sunlit experiment. To estimate the influence of wall loss changes on our result, the LSQ fit was repeated with $\pm 50 \%$ higher and lower wall loss rates. As a result $k(\mathrm{OH}+\mathrm{MEA})$ varied by $\pm 24 \%$. In a second test the wall loss rate was increased linearly over time until it reached a $50 \%$ higher value at the end of the selected time period of $1300 \mathrm{~s}$. This resulted in a decrease of the slope $b$ by $22 \%$. It is emphasized that the experimentally derived $k_{\text {wall }}$ before and after the sunlit experiments never showed larger variations than given by the standard deviation (ca. $\pm 35 \%$, see Table 5).

Presence of the nitrate radical $\left(\mathrm{NO}_{3}\right)$ during the experiments may have introduced an unmeasured interference due to the competing reaction of $\mathrm{NO}_{3}$ radicals with MEA. Experiments were performed under full sunlight and $\mathrm{NO}_{3}$ undergoes rapid photolysis under such conditions. Modelled $\mathrm{NO}_{3}$ concentrations were highest at the start of the experiments with a maximum value of $4 \times 10^{7}$ radicals $\mathrm{cm}^{-3}$, while modelled $\mathrm{OH}$ concentrations were $\backsim 5 \times 10^{6}$ radicals cm $\mathrm{cm}^{-3}$. The rate constant of the reaction $\mathrm{NO}_{3}+\mathrm{MEA}$ is not known from experiments and EPI Suite currently offers no possibility to estimate rate constants of $\mathrm{NO}_{3}$ reactions. Using the new quantitative structure-property relationship (QSPR) for $\mathrm{NO}_{3}$ degradation of VOC given by Papa and Gramatica (2008), the molecular descriptors HOMO (highest occupied molecular orbital) computed with the molecular modelling software CAChe system (2000-2005 Fuijtsu Limited) using semi empirical quantum mechanics (MOPAC PM3), and Me (mean atomic electronegativity of Sanderson) computed by DRAGON software version 6 (Todeschini et al., 2011), a value of $1.48 \times 10^{-13} \mathrm{~cm}^{3}$ molecule ${ }^{-1} \mathrm{~s}^{-1}$ was calculated for this rate constant (Heimstad, E. S., personal communication, 2011) The rate constant value is in good agreement with the SAR estimate of $1.35 \times 10^{-13} \mathrm{~cm}^{3}$ molecule ${ }^{-1} \mathrm{~s}^{-1}$ provided by Carter (2008). Based on model calculations using the rate constant value estimated here, the $\mathrm{NO}_{3}+$ MEA reaction is predicted to contribute at the most $4 \%$ to the overall decay of MEA.

The error of the model-derived particle loss rate, $k_{\text {particles}}$, is estimated to be $\pm 15 \%$ due to the instrumental error of AMS and the error of the nitrate signal. The loss of MEA to particles has been found to be a minor contribution $(<4 \%)$ to the overall loss of MEA during the kinetic experiments.

The only other temperature-dependent rate data for the reaction of $\mathrm{OH}$ radicals with TMB is published by Geiger et al. (2002). For the temperature range of $278-320 \mathrm{~K}$ their expression is $k_{\text {ref }}=6.3 \times 10^{-12} \exp (670 / T)$ (Geiger et al., 2002; Aschmann et al., 2006). Rate constants calculated using this expression are uniformly higher by $11-15 \%$ over the temperature range $278-320 \mathrm{~K}$ than those calculated using the expression by Aschmann et al. (2006). In our data analysis, the use of the expression by Geiger et al. (2002) would imply a higher rate constant for the reaction of $\mathrm{OH}$ with MEA, by $14 \%$ and $15 \%$ in experiment E1 and E2, respectively.

Using the LSQ model with the MEA mixing ratio measured by FT-IR (time-synchronized on the PTR-MS grid) instead of the HT-PTR-MS data resulted in a $9 \%$ and $30 \%$ lower rate constant estimate in E1 and E2, respectively. However, the MEA time series from FT-IR are less accurate because of the possible presence of unknown compounds that absorb in the same spectral region as MEA. Figure $3 a$ and $b$ show that there were no systematic discrepancies for the MEA measurement by both instruments, but the time series show different slopes, in particular when mixing ratios are small. 

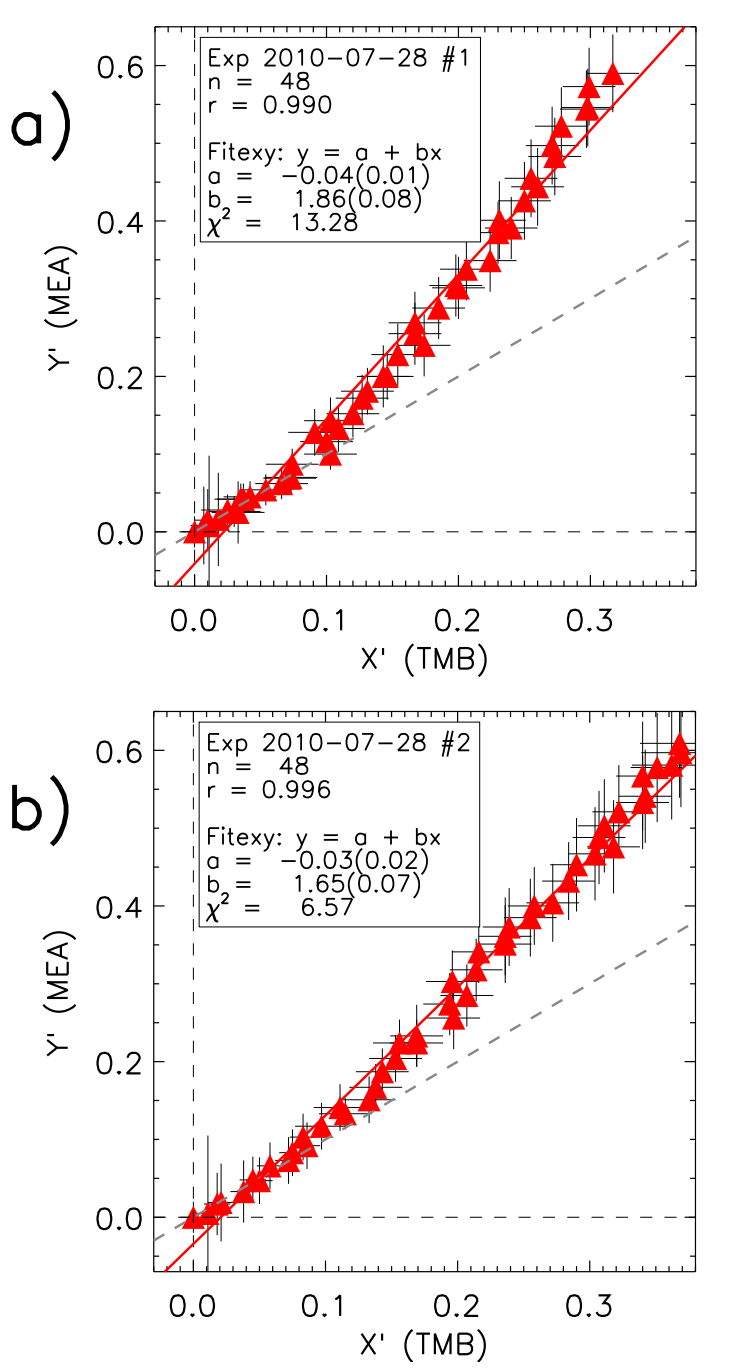

Fig. 4. Results of the fit for $X^{\prime}$ (horizontal axis) and $Y^{\prime}$ (vertical axis) according to Eq. (11) for (a) experiment E1 and (b) experiment E2. The experiment period used in the relative rate determination was $1300 \mathrm{~s}$ as indicated by horizontal yellow bars in Fig. 3. The result from the least-squares fit (LSQ) is indicated by the straight red line. Fit parameters for E1 are $a=-0.04 \pm 0.01, b=1.86 \pm 0.08$, $\chi^{2}=13.28$ and for E2 are $a=-0.03 \pm 0.02, b=1.65 \pm 0.07, \chi^{2}=$ 6.57. The grey dashed line represents the $1: 1$ line. The error bars indicate $1-\sigma$ statistical errors of both $X^{\prime}$ and $Y^{\prime}$ and these errors include measurement errors of TMB (for $X^{\prime}$ ) and MEA (for $Y^{\prime}$ ) mixing ratios and estimated errors of loss rates $L$ and $D_{\mathrm{SF}_{6}}$.

Systematic errors of the measurements of MEA and of TMB mixing ratios are cancelled out in our data analysis, since both compounds were measured by the HT-PTR-MS. The good agreement between TMB mixing ratios measured by HT-PTR-MS and GC-PID confirms the high accuracy of the TMB measurement. The overall (systematic) error of the rate constants determined in this work is composed of the error of the reference rate constant, $k_{\text {ref }}$, given by $\pm 12 \%$ (Aschmann et al., 2006) and the error of the MEA wall loss

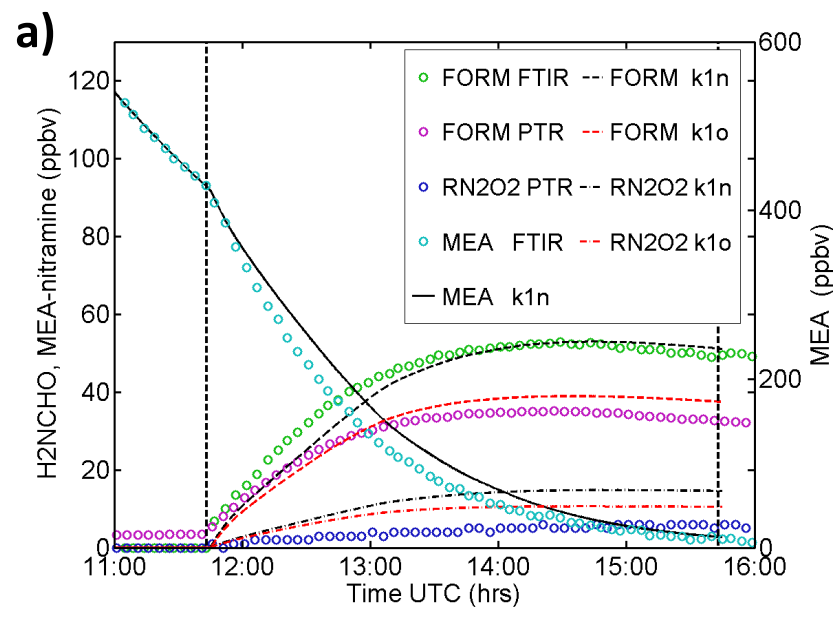

b)

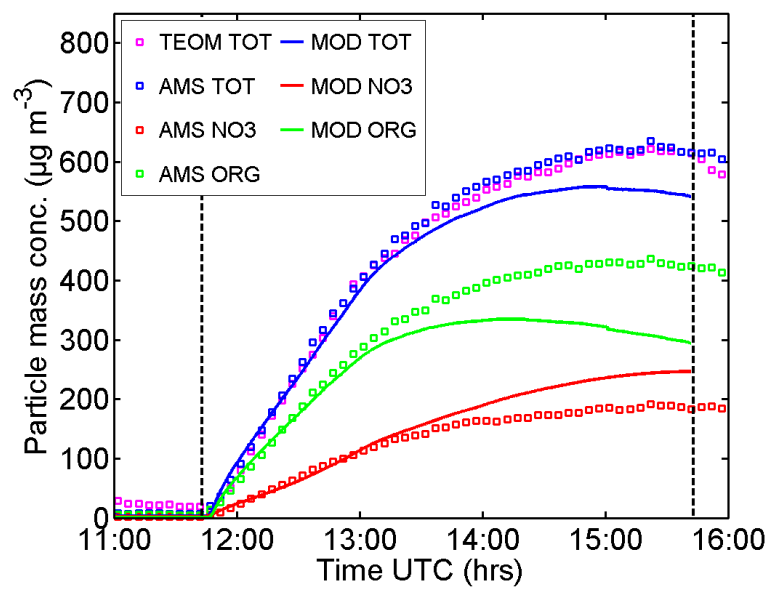

Fig. 5. Concentration time series of experiment E3 on 27 July 2010: (a) measured gas phase concentrations of MEA (FT-IR), formamide (FT-IR and PTR-TOF-MS)), 2-nitroamino ethanol (PTRTOF-MS), and modelled concentrations of formamide (FORM) and 2-nitroamino ethanol ( $\mathrm{RN} 2 \mathrm{O} 2)$ using the $k(\mathrm{OH}+\mathrm{MEA})$ value from EPI Suite v4.0 (red lines, "k1o") and the value derived in this work (black lines, "k1n"), (b) measured and modelled mass concentrations of nitrate $\left(\mathrm{NO}_{3}\right)$, high-molecular weight organics $>m / z 65$ (ORG), and total (TOT) particles. Measured total particle mass data from AMS (blue squares) and TEOM (magenta squares) are in agreement. For better visibility, modelled nitramine concentrations were scaled by a factor of 5 and measured nitramine concentrations were scaled by a factor of 100 . Vertical dashed lines indicate beginning and end of the sunlit experiment.

rate which translates into a $\pm 24 \%$ error, and is estimated to be $\pm 27 \%$.

\subsection{Particle formation}

Amines have high particle formation potential and nucleation of particles followed by fast growth has been observed in sunlit chamber experiments with MEA (Murphy et al., 2007; Carter, 2008; Karl et al., 2010). Presence of the ionic form of dimethylamine, i.e. dimethyl aminium cation, 

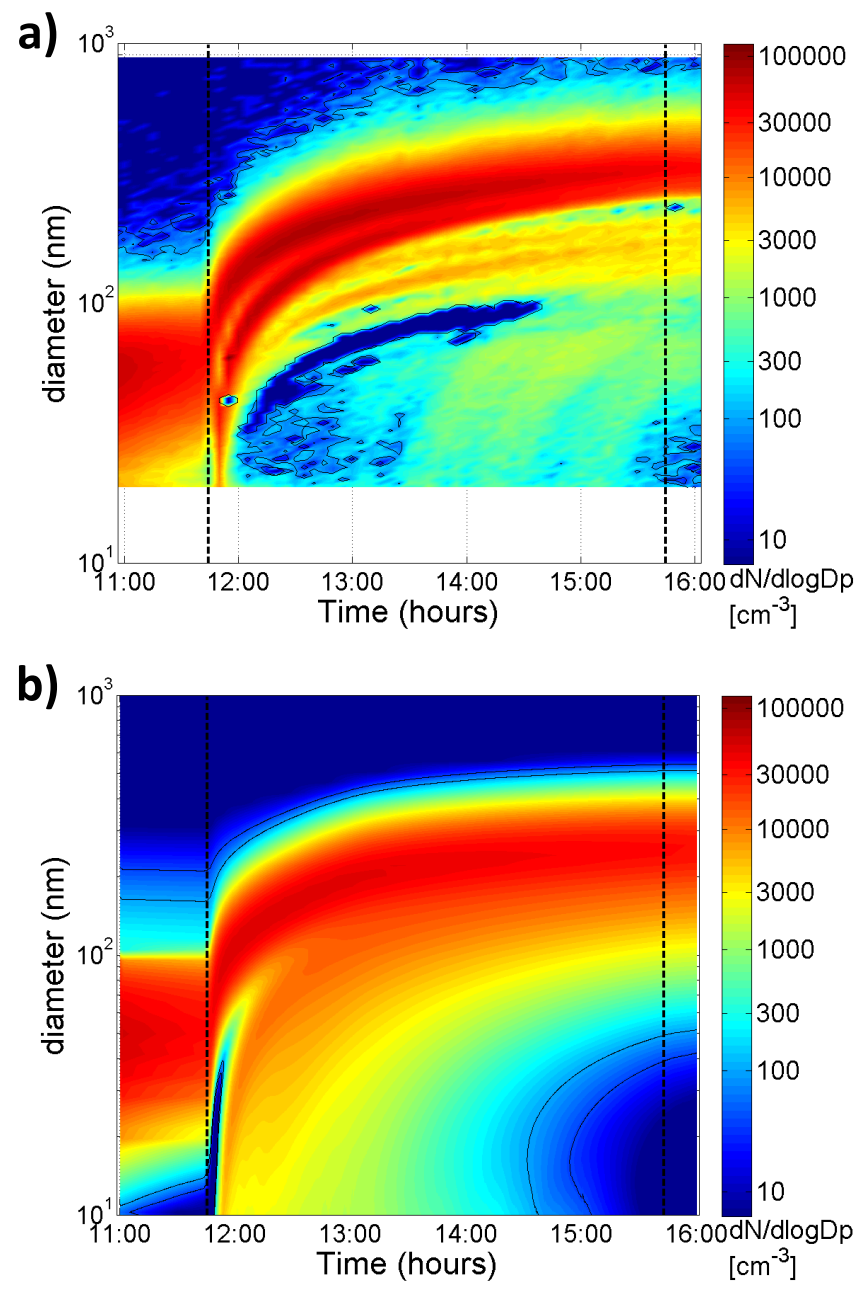

Fig. 6. Sequential number size distribution $\left(d N / d \log D_{\mathrm{p}}\right.$ in $\# \mathrm{~cm}^{-3}$ ) during experiment E3 (a) recorded by the SMPS, (b) obtained from a simulation with MAFOR. Diameter range shown is from $10 \mathrm{~nm}$ to $1000 \mathrm{~nm}$. The lower size cut-off of the SMPS instrument was at $19.5 \mathrm{~nm}$. Vertical black dashed lines indicate beginning and end of the sunlit experiment.

in nucleation mode particles in boreal and marine environments led to the speculation that amines are strongly involved in post-nucleation growth (Mäkelä et al., 2001; Facchini et al., 2008). Amines may also directly participate in the first steps of nucleation, e.g. by formation of dimer clusters with sulphuric acid. Short-chained aliphatic amines like dimethylamine and trimethylamine seem to be more important than ammonia $\left(\mathrm{NH}_{3}\right)$ in enhancing sulphuric acidwater nucleation in the atmosphere, even though their atmospheric concentrations are usually $2-3$ orders lower than that of $\mathrm{NH}_{3}$ (Kurtén et al., 2008; Bzdek et al., 2010; Erupe et al., 2011). Murphy et al. (2007) observed nucleation within minutes after injection of amines in a chamber containing gaseous $\mathrm{HNO}_{3}$. In this work we have assumed that new particle formation observed in MEA oxidation exper- iments occurs through homogenous heteromolecular nucleation between $\mathrm{HNO}_{3}$ and MEA vapour molecules. Since initial $\mathrm{HNO}_{3}$ mixing ratios were very low in the experiments the main source of $\mathrm{HNO}_{3}$ was the reaction of photochemically produced $\mathrm{OH}$ with $\mathrm{NO}_{2}$.

This is consistent with the observed delayed start of the nucleation burst by a few minutes after opening of the chamber canopy (Fig. 6a). Both measured and modelled number size distribution $\left(d N / d \log D_{\mathrm{p}}\right)$ show two separate bursts in experiment E3; the first burst after exposing the chamber to light was formed by nucleation mode particles that had been generated in the dark chamber and grew by condensation of vapours, while the second burst (the nucleation burst) was formed by growing particles that nucleated shortly afterwards (Fig. 6a and b). The diameter of the growth curve (diameter of the $d N / d \log D_{\mathrm{p}}$ peak) at the end of the experiment was $322 \mathrm{~nm}$ in the size distribution measured by SMPS and $242 \mathrm{~nm}$ in the size distribution obtained from the MAFOR simulation.

The observed nucleation of MEA and $\mathrm{HNO}_{3}$ could be relevant for the atmosphere since the high numbers of particles which were produced in our experiments remained even after MEA had been largely depleted. Dissociation coefficients for aminium nitrate salts are typically one order of magnitude smaller than that of ammonium nitrate at the same temperature, with the exception of trimethylamine (Ge et al., 2011b). A recent flow tube study by Lloyd et al. (2009) demonstrated that trimethylamine can be taken up by ammonium nitrate particles, leading to an exchange of trimethylamine for $\mathrm{NH}_{3}$ in the particles.

The theoretical $K_{p}$ value of ethanolaminium nitrate which was used in this work is uncertain and it was not possible to determine the true $K_{p}$ value. Salo et al. (2011) used a volatility tandem differential mobility analyzer (VTDMA) to determine the volatility properties of alkyl aminium and ethanol aminium nitrate particles. For the ethanol aminium nitrate particles the derived vapour pressure was $8.9 \times 10^{-5} \mathrm{~Pa}$ (at $298 \mathrm{~K})$ with an uncertainty range of $(5.9-12.9) \times 10^{-5} \mathrm{~Pa}$. Based on the measured vapour pressure by Salo et al. (2011) the value $K_{p}=7.37 \times 10^{-10} \mathrm{~Pa}^{2}$ at $293.15 \mathrm{~K}$ for the MEA nitrate is estimated using the simple relationship $K_{p}$ (in units $\left.\mathrm{Pa}^{2}\right)=\left(p^{0} / 2\right)^{2}$ (Mozurkewich, 1993). The experimental value is two orders of magnitude higher than the value estimated based on thermodynamic data for vapour-solution equilibria by Ge et al. (2011b). We therefore suggest that the $K_{p}$ of ethanolaminium nitrate should be studied in chamber experiments with MEA and $\mathrm{NH}_{3}$ as competing reactants for $\mathrm{HNO}_{3}$.

The mass-based fraction of the nitrate salt in the chamber aerosol according to the AMS measurements was $23 \%$, $24 \%$, and $30 \%$, respectively, at the end of experiments E1, $\mathrm{E} 2$, and E3. The corresponding mass-based fractions of the nitrate salt predicted by MAFOR were $14 \%, 20 \%$, and $46 \%$ in E1, E2, and E3, respectively. Given that ethanolaminium nitrate contributed $80 \%$ to the measured 
nitrate salt concentrations, the agreement is good in E1 and E2. In the case of E3 it is noted that the agreement between modelled and measured nitrate salt concentration is very good in the first two hours of the experiment (Fig. 5b). The deviation of the modelled concentration at later experiment time can be explained by the uncertainties of $K_{p}$ and of the $\mathrm{HNO}_{3}$ production rate in the model.

The mass-based fraction of organics, attributed to SOA, measured by AMS was $68-76 \%$ in experiments E1, E2, and E3. The high contribution of secondary (non-salt) organics to the aerosol formed in the $\mathrm{OH}$-initiated oxidation of MEA has not been reported before and is likely a result of favourable conditions in the experiments such as sufficiently high $\mathrm{OH}-$ levels. The non-salt organic fraction of the aerosol partly consists of relatively high-molecular organics $(>m / z 65)$, mainly $\mathrm{C}_{3}$ and $\mathrm{C}_{4}$ compounds, however individual compounds could not be identified.

The SOA formation in the presented experiments could be adequately described with a one-product approach. This work uses succinic acid, a dicarboxylic acid, to represent SOA compounds from MEA oxidation. The vapor pressure of succinic acid and its temperature dependence adopted from Bilde et al. (2003) was used for MEAp1. The vapor pressure of succinic acid at $293.15 \mathrm{~K}$ is calculated to be $1.64 \times 10^{-5} \mathrm{~Pa}$ using the data by Bilde et al. (2003). The dissociation constant of MEA nitrate particles used in this work is $1.41 \times 10^{-12} \mathrm{~Pa}^{2}$ at $293.15 \mathrm{~K}$, adopted from Ge et al. (2011b), which translates into a vapor pressure of $2.37 \times 10^{-6} \mathrm{~Pa}$ using the relationship mentioned above. Thus in the one-product model approach, the SOA compound has a higher volatility than MEA nitrate.

\subsection{Impact on health and environment}

Formamide, one of the major gaseous oxidation products from MEA (Nielsen et al., 2011), will be oxidized to form isocyanic acid $(\mathrm{H}-\mathrm{N}=\mathrm{C}=\mathrm{O})$ in the atmosphere (Barnes et al., 2010). Isocyanic acid reacts only slowly with $\mathrm{OH}$ and other atmospheric oxidants (Wooldridge et al., 1996) and, due to its high solubility, will be taken up in water droplets and finally be removed from the atmosphere by wet deposition. In the aqueous phase, isocyanic acid may undergo hydrolysis to form ammonia and carbon dioxide. Toxic information on isocyanic acid is sparse. Although there is no direct evidence that isocyanic acid can cause respiratory sensitisation, it is a biologically reactive compound and can cause damage to biological systems (Shah et al., 2008). Exposure to elevated levels ( $>1 \mathrm{ppbv}$ ) of isocyanic acid and its dissociated form, the cyanate ion $\left(\mathrm{NCO}^{-}\right)$, have been related to atherosclerosis, cataracts, rheumatoid arthritis, and asthma (Baur et al., 1994; Piirilä et al., 2000; Sennbro et al., 2004).

Nitramines may have carcinogenic effects and, in contrary to nitrosamines, are photochemically stable in the atmosphere (Grosjean, 1991) and can have atmospheric lifetimes of more than 2 days. Using atmospheric average 12-h daytime $\mathrm{OH}$ concentrations of $1.5 \times 10^{6}$ radicals $^{-3}$ and the reported rate constant for the reaction with $\mathrm{OH}$ radicals (Tuazon et al., 1984), updated with the recommended value for the reference rate of $\mathrm{CH}_{3} \mathrm{OCH}_{3}$ $\left(k\left(\mathrm{OH}+\mathrm{CH}_{3} \mathrm{OCH}_{3}\right)=2.8 \times 10^{-12} \mathrm{~cm}^{3}\right.$ molecule ${ }^{-1} \mathrm{~s}^{-1}$ at $298 \mathrm{~K}$; IUPAC, 2009), the atmospheric lifetime of dimethylnitramine is estimated to be 2.4 days. Using the estimated rate constant of $\mathrm{OH}$ radicals with 2-nitroamino ethanol obtained by EPI Suite version 4.0, indicates a shorter lifetime for this nitramine, i.e. $\backsim 0.5$ days. To evaluate the health risk of nitramines which form in the atmospheric degradation of amines, further studies on their toxicity and reactivity towards $\mathrm{OH}$ radicals are recommended.

The environmental impact of MEA emissions from a $\mathrm{CO}_{2}$ capture facility due to formation and dispersion of hazardous oxidation products, photochemical ozone and particulate matter can only be realistically assessed by application of a state-of-the-art 3-D atmospheric chemistry transport model (CTM) which includes details of the MEA chemistry. Compressed chemistry mechanisms for several amines have been added to the SAPRC-07 mechanism (Carter, 2010). However, these compressed mechanisms could not be evaluated in chamber experiments because of the difficulties with respect to amine quantification. The gas-phase mechanism for the $\mathrm{OH}$-initiated oxidation of MEA presented in this work can be readily implemented in large scale models by using the kinetic pre-processor as for example in the WRF/Chem community model (Grell et al., 2005; http://ruc.noaa.gov/wrf/ WG11/). When a CTM with a dedicated chemistry solver is used, it will be necessary to simplify the presented set of reactions. This should be done carefully in order to preserve important features of the MEA chemistry such as the $\mathrm{NO}_{\mathrm{x}}{ }^{-}$ dependence of the nitramine formation.

\section{Conclusions}

With the help of advanced instrumentation (HT-PTR-MS and AMS) it was possible to determine the reaction rate constant $k(\mathrm{OH}+\mathrm{MEA})$ relative to the rate constant of the $\mathrm{OH}+1,3,5-$ trimethylbenzene reaction in EUPHORE. The chamber aerosol model MAFOR was applied to quantify losses of MEA to the particle phase. The rate constant $k(\mathrm{OH}+\mathrm{MEA})$ was found to be $(9.2 \pm 1.1) \times 10^{-11} \mathrm{~cm}^{3}$ molecule ${ }^{-1} \mathrm{~s}^{-1}$ (at $298 \mathrm{~K})$ as an average of two similar experiments. The reaction between $\mathrm{OH}$ radicals and MEA is a factor of 2-3 faster than estimated by SAR methods.

Due to the large instrumental effort connected with experiments in EUPHORE, only two experiments were carried out to determine the rate constant. The reproducibility of photooxidation experiments in EUPHORE has been demonstrated earlier (e.g. Bloss et al., 2005a). The good agreement of the rate constant values obtained in the two experiments of this study further underlines this. Wall loss of MEA was found to be the main uncertainty in the rate determination 
experiments. We estimated the maximum (systematic) error of the resulting rate constant due to uncertain wall effects to be $\pm 24 \%$. A further complication was the possible presence of $\mathrm{NO}_{3}$ radicals which may react relatively fast with MEA. However, model calculations showed that the $\mathrm{NO}_{3}+\mathrm{MEA}$ reaction accounted for $4 \%$ of the total loss rate of MEA at the most. The possible error of the rate constant $k(\mathrm{OH}+\mathrm{MEA})$ due to $\mathrm{NO}_{3}$ reaction was estimated to be smaller than $2 \%$.

Interestingly, the higher $\mathrm{OH}$-reaction rate constant value found for MEA is close to rate constant values estimated by EPI Suite v4.0 for other ethanolamines. The estimated rate constants for the OH-reactions of diethanolamine (DEA) and triethanolamine (TEA) are $9.3 \times 10^{-11} \mathrm{~cm}^{3}$ molecule ${ }^{-1} \mathrm{~s}^{-1}$ and $11.1 \times 10^{-11} \mathrm{~cm}^{3}$ molecule $\mathrm{s}^{-1}$ (at $298 \mathrm{~K}$ ), respectively. Two computational studies published in a report by Angove et al. (2010) demonstrate that hydrogen abstraction from the hydroxyl group $(-\mathrm{OH})$ of MEA is a major pathway of its $\mathrm{OH}$-initiated oxidation. This may serve as a mechanistic explanation for the higher rate constant value obtained in the experiments compared to the SAR methods where Habstraction at $-\mathrm{OH}$ is only a minor contribution to the overall rate constant value.

The higher rate constant value has implications for predicted atmospheric concentrations of 2-nitroamino ethanol and formamide which are produced in the photo-oxidation of MEA. Predicted steady-state concentrations of 2nitroamino ethanol and formamide increased by $39 \%$ and $36 \%$, respectively, when applying the experimentally derived $k(\mathrm{OH}+\mathrm{MEA})$ value. However, comparison of modelled and measured concentrations of 2-nitroamino ethanol indicates that the model currently overestimates the production yield of the nitramine by at least a factor of 5 .

Further experiments in reactor systems, for example flow tube or flash photolysis systems, where adsorption of MEA to surfaces is prevented, are needed to improve the accuracy of $k(\mathrm{OH}+\mathrm{MEA})$. Alternatively, a better characterization of the MEA wall loss in EUPHORE would reduce the uncertainty of the rate constant. The observation of high aerosol formation potential in the photo-oxidation of MEA should encourage further experiments to better quantify the factors affecting nucleation of new particles and their growth.

\section{Appendix A}

\section{Relative rate equation}

Integration of the balances equations in Eq. (9) from $t^{\prime}=0$ to $t^{\prime}=t$ gives the following set of equations:

$$
\begin{aligned}
\ln \left(\frac{<\operatorname{MEA}(0)>}{<\operatorname{MEA}(t)>}\right) & =k_{1} \int_{0}^{t}[\mathrm{OH}] \mathrm{d} t^{\prime}+\int_{0}^{t} k_{\mathrm{dil}}\left(t^{\prime}\right) \mathrm{d} t^{\prime} \\
& +\int_{0}^{t}\left(k_{\mathrm{wall}}\left(t^{\prime}\right)+k_{\text {particles }}\left(t^{\prime}\right)\right) \mathrm{d} t^{\prime}
\end{aligned}
$$

For the analyzed time period of the experiment, temperature was almost constant and it is thus assumed that the $\mathrm{OH}$ rate constants $k_{1}$ and $k_{\text {ref }}$ do not vary over time. Introducing short-cuts for the logarithmic relative concentrations,

$$
\begin{gathered}
Y_{\mathrm{MEA}}(t)=\ln \left(\frac{<\operatorname{MEA}(0)>}{<\operatorname{MEA}(t)>}\right) \\
X_{\mathrm{TMB}}(t)=\ln \left(\frac{<\mathrm{TMB}(0)>}{<\mathrm{TMB}(t)>}\right) \\
D_{\mathrm{SF}_{6}}(t)=\ln \left(\frac{<\mathrm{SF}_{6}(0)>}{<\mathrm{SF}_{6}(t)>}\right)
\end{gathered}
$$

and an integrated loss rate,

$$
L(t)=\int_{0}^{t}\left(k_{\text {wall }}\left(t^{\prime}\right)+k_{\text {particles }}\left(t^{\prime}\right)\right) \mathrm{d} t^{\prime}
$$

results in a modified relative rate equation:

$Y_{\mathrm{MEA}}(t)-D_{\mathrm{SF}_{6}}(t)-L(t)=\frac{k_{1}}{k_{\mathrm{ref}}}\left(X_{\mathrm{TMB}}(t)-D_{\mathrm{SF}_{6}}(t)\right)$

This expression can be further simplified by introducing new variables which can be calculated based on measured time series:

$$
\begin{aligned}
& Y_{\mathrm{MEA}}^{\prime}(t)=Y_{\mathrm{MEA}}(t)-D_{\mathrm{SF}_{6}}(t)-L(t) \\
& X_{\mathrm{TMB}}^{\prime}(t)=X_{\mathrm{TMB}}(t)-D_{\mathrm{SF}_{6}}(t)
\end{aligned}
$$

By replacing the terms in Eq. (A8) with $Y_{\mathrm{MEA}}^{\prime}$ and $X_{\mathrm{TMB}}^{\prime}$ as given in Eq. (A9) and Eq. (A10), a standard relative rate equation is derived.

Acknowledgements. The Instituto Universitario CEAM-UMH is partly supported by Generalitat Valenciana, Fundación Bancaja, and the projects GRACCIE (Consolider-Ingenio 2010) and FEEDBACKS (Prometeo - Generalitat Valenciana). The EUPHORE team is acknowledged for their support in the use of the facilities. Armin Wisthaler and Tomas Mikoviny acknowledge support from A. Hansel and T. D. Märk. Claus Nielsen is thanked for the preparation of the reference salt, ethanolaminium nitrate, for the AMS analysis. Eldbjørg S. Heimstad and Mikael Harju (NILU Tromsø) are thanked for determination of rate constants of several products from $\mathrm{OH}$-initiated oxidation of MEA using EPI Suite version 4.0.

Edited by: J. B. Burkholder 


\section{References}

Angelino, S., Suess, D. T., and Prather, K. A.: Formation of aerosol particles from reactions of secondary and tertiary alkylamines: Characterization by aerosol time-of-flight mass spectrometry, Environ. Sci. Technol., 40, 3130-3138, 2001.

Angove, D., Jackson, P., Lambropoulos, N., Azzi, M., and Attalla, M.: $\mathrm{CO}_{2}$ Capture Mongstad - Project B - Theoretical evaluation of the potential to form and emit harmful compounds, CSIRO Report, available at: http://www.gassnova.no/frontend/files/ CONTENT/Rapporter/AtmosphericFormation_CSIRO.pdf, 2010.

Aschmann, S. M., Long, W. D., and Atkinson, R.: Temperaturedependent rate constants for the gas-phase reactions of $\mathrm{OH}$ radicals with 1,3,5-trimethylbenzene, triethyl phosphate, and a series of alkylphosphonates. J. Phys. Chem. A, 110, 7393-7400, 2006.

Bakovic, M., Fullerton, M. D., and Michel, V.: Metabolic and molecular aspects of ethanolamine phospholipid biosynthesis: the role of CTP: phosphoethanolamine cytidylyltransferase (Pcyt2). Biochem. Cell Biol., 85, 283-300, 2007.

Barnes, I., Solignac, G., Mellouki, A., and Becker, K. H.: Aspects of the atmospheric chemistry of amides, Chem. Phys. Chem., 11, 3844-3857, 2010.

Baur, X., Marek, W., Ammon, J., Czuppon, A. B., Marczynski, B., Raulf-Heimsoth, M., Roemmelt, H., and Fruhmann, G.: Respiratory and other hazards of isocyanates, Int. Arch. Occup. Environ. Health, 66, 141-152, 1994.

Becker, K. H.: The European photoreactor EUPHORE. Final report of the EC-Project contract EV5V-CT02-0059, Physikalische Chemie, Bergische Universität-Gesamthochschule Wuppertal, Wuppertal, Germany, 1996.

Bilde, M., Svenningsson, B., Monster, J., and Rosenørn, T.: Evenodd alternation of evaporation rates and vapor pressures of C3C9 dicarboxylic acid aerosols, Environ. Sci. Technol., 37, 13711378, 2003.

Bloss, C., Wagner, V., Bonzanini, A., Jenkin, M. E., Wirtz, K., Martin-Reviejo, M., and Pilling, M. J.: Evaluation of detailed aromatic mechanisms (MCMv3 and MCMv3.1) against environmental chamber data, Atmos. Chem. Phys., 5, 623-639, doi:10.5194/acp-5-623-2005, 2005a.

Bloss, C., Wagner, V., Jenkin, M. E., Volkamer, R., Bloss, W. J., Lee, J. D., Heard, D. E., Wirtz, K., Martin-Reviejo, M., Rea, G., Wenger, J. C., and Pilling, M. J.: Development of a detailed chemical mechanism (MCMv3.1) for the atmospheric oxidation of aromatic hydrocarbons, Atmos. Chem. Phys., 5, 641-664, doi:10.5194/acp-5-641-2005, 2005b.

Brauers, T. and Finlayson-Pitts, B. J.: Analysis of relative rate measurements, Int. J. Chem. Kinet., 29, 665-672, 1997.

Bråten, H. B., Bunkan, A. J., Bache-Andreassen, L., Solimannejad, M., and Nielsen, C. J.: Final report on a theoretical study on the atmospheric degradation of selected amines, NILU OR 77/2008, Norwegian Institute for Air Research, Kjeller, Norway, available at: http://www.nilu.no, 2008.

Bzdek, B. R., Ridge, D. P., and Johnston, M. V.: Amine exchange into ammonium bisulfate and ammonium nitrate nuclei, Atmos. Chem. Phys., 10, 3495-3503, doi:10.5194/acp-10-3495-2010, 2010.

Carter, W. P. L.: Reactivity estimates for selected consumer product compounds, Final Report, Contract No. 06-408, Center for Environmental Research and Technology, College of Engineering,
University of California, Riverside, California, USA, available at: http://www.engr.ucr.edu/ carter/pubs/aminrep.pdf, 2008.

Carter, W. P. L.: Development of the SAPRC-07 chemical mechanism and updated ozone reactivity scales, Report to the California Air Resources Board, Contracts No. 03-318, 06-408, and 07-730, Riverside CA, USA, available at: http://www.cert.ucr. edu/ $\sim$ carter/SAPRC/saprc07.pdf, 2010.

Cocker, D. R., Mader, B. T., Kalberer, M., Flagan, R. C., and Seinfeld, J. H.: The effect of water on gas-particle partitioning of secondary organic aerosol: II. m-xylene and 1,3,5-trimethylbenzene photooxidation systems, Atmos. Environ., 35, 6073-6085, 2001.

DiGuilio, R. M., Lee, R. J., Schaeffer, S. T., Brasher, L. L., and Teja, A. S.: Densities and viscosities of the ethanolamines, J. Chem. Eng. Data, 37, 239-242, 1992.

Dow Chemicals, available at: http://www.dow.com/amines/prod/ ethano-mea.htm, last access: 30 November 2011c, 2011.

Drewnick, F., Hings, S. S., DeCarlo, P. F., Jayne, J. T., Gonin, M., Fuhrer, K., Weimer, S., Jimenez, J. L., Demerjian, K. L., Borrmann, S., and Worsnop, D. R.: A new Time-of-Flight Aerosol Mass Spectrometer (ToF-AMS) - Instrument Description and First Field Deployment, Aerosol Sci. Technol., 39, 637-658, 2005.

Erupe, M. E., Viggiano, A. A., and Lee, S.-H.: The effect of trimethylamine on atmospheric nucleation involving $\mathrm{H}_{2} \mathrm{SO}_{4}$, Atmos. Chem. Phys., 11, 4767-4775, doi:10.5194/acp-11-47672011, 2011.

Facchini, M. C., Decesari, S., Rinaldi, M., Carbone, C., Finessi, E., Mircea, M., Fuzzi, S., Moretti, F., Tagliavini, E., Ceburnis, D., and O'Dowd, C. D.: Important source of marine secondary organic aerosol from biogenic amines. Environ. Sci. Technol., 42, 9116-9121, 2008.

Fahlman, A.: A modified Marquardt-Levenberg parameter estimation routine for Matlab, Report NMRC 01-002, Naval Medical Research Institute, Bethesda, MD, USA, 2001.

Fournier, M., Lesage, J., Ostiguy, C., and Tra, H. V.: Sampling and analytical methodology development for the determination of primary and secondary low molecular weight amines in ambient air, J. Environ. Monit., 10, 379-386, 2008.

Fuchs, N. A. and Sutugin, A. G.: Highly Dispersed Aerosols, Ann. Arbor Sci., Ann Arbor, Mich., USA, 1970.

Ge, X., Wexler, A. S., and Clegg, S. L.: Atmospheric amines - Part I: A review, Atmos. Environ., 45, 524-546, $2011 \mathrm{a}$.

Ge, X., Wexler, A. S., and Clegg, S. L.: Atmospheric amines Part II: Thermodynamic properties and gas/particle partitioning, Atmos. Environ., 45, 561-577, 2011 b.

Geier, J., Lessmann, H., Dickel, H., Frosch, P. J., Koch, P., Becker, D., Jappe, U., Aberer, W., Schnuch, A., Uter, W.: Patch test results with the metalworking fluid series of the German Contact Dermatitis Research Group (DKG), Contact Dermatitis, 51, 118130, 2004.

Geiger, H., Barnes, I. Becker, K. H., Bohn, B., Brauers, T., Donner, B., Dorn, H.-P., Elend, M., Freitas Dinis, C. M., Grossmann, D., Hass, H., Hein, H., Hoffmann, A., Hoppe, L., Hülsemann, F., Kley, D., Klotz, B., Libuda, H. G., Maurer, T., Mihelcic, D., Moortgat, G. K., Olariu, R., Neeb, P., Poppe, D., Ruppert, L., Sauer, C. G., Shestakov, O., Somnitz, H., Stockwell, W. R., Thüner, L. P., Wahner, A., Wiesen, P., Zabel, F., Zellner, R., and Zetzsch, C.: Chemical mechanism development: Laboratory study and model applications, J. Atmos. Chem., 42, 323-357, 
2002.

Goff, G. S. and Rochelle, G. T.: Monoethanolamine degradation: $\mathrm{O}_{2}$ mass transfer effects under $\mathrm{CO}_{2}$ capture conditions, Ind. Eng. Chem. Res., 43, 6400-6408, 2004.

Goodall, C. M. and Kennedy, T. H.: Carcinogenicity of dimethylnitramine in NZR rats and NZO mice, Cancer Lett., 1, 295-298, 1976.

Güsten, H.: Predicting the abiotic degradability of organic pollutants in the troposphere, Chemosphere, 38, 1361-1370, 1999.

Grell, G. A., Peckham, S. E., Schmitz, R., McKeen, S. A., Frost, G., Skamarock, W. C., and Eder, B.: Fully coupled online chemistry within the WRF model, Atmos. Environ., 39, 6957-6975, 2005.

Grosjean, D.: Atmospheric chemistry of toxic contaminants: 6. Nitrosamines: Dialkyl nitrosamines and nitrosomorpholine, J. Air Waste Manage. Assoc., 41, 306-311, 1991.

Hassel, M., Frei, E., Streeter, A. J., and Wiessler, M.: Pharmakokinetics of $\mathrm{N}$-nitrodimethylamine and $\mathrm{N}$-nitromethylamine in the rat, Carcinogenesis, 11, 357-360, 1990.

IUPAC Subcommittee for Gas Kinetic Data Evaluation 2009, Evaluated kinetic data, http://www.iupac-kinetic.ch.cam.ac.uk/index. html, last access:5 July 2011, 2009.

Jacobson, M. Z.: Numerical techniques to solve condensational and dissolutional growth equations when growth is coupled to reversible reactions, Aerosol Sci. Technol., 27, 491-498, 1997.

Jacobson, M. Z.: Effects of ethanol (E85) versus gasoline vehicles on cancer and mortality in the United States, Environ. Sci. Technol., 41, 4150-4157, 2007.

Jordan, A., Haidacher, S., Hanel, G., Hartungen, E., Märk, L., Seehauser, H., Schottkowsky, H., Sulzer, P., and Märk, T. D.: A high resolution and high sensitivity proton-transfer-reaction time-of-flight mass spectrometer (PTR-TOF-MS), Int. J. Mass Spectrom., 286, 122-128, 2009.

Kapteina, S., Slowik, K., Verevkin, S. P., and Heintz, A.: Vapor pressures and vaporization enthalpies of a series of ethanolamines. J. Chem. Eng. Data, 50, 398-402, 2005.

Karl, M., Gross, A., Leck, C., and Pirjola, L.: Intercomparison of dimethylsulfide oxidation mechanisms for the marine boundary layer: Gaseous and particulate sulfur constituents, J. Geophys. Res., 112, D15304, doi:10.1029/2006JD007914, 2007.

Karl, M., D’Anna, B., George, C., King, S., Wisthaler, A., Dye, C., and Nielsen, C. J.: Particle formation in photo-oxidation experiments with 2-aminoethanol (MEA), Geophys. Res. Abs., 12, EGU2010-8196, 2010.

Karl, M., Wright, R. F., Berglen, T. F., and Denby, B.: Worst case scenario study to assess the environmental impact of amine emissions from a $\mathrm{CO}_{2}$ capture plant, Int. J. Greenhouse Gas Control, 5, 439-447, 2011a.

Karl, M., Gross, A., Leck, C., and Pirjola, L.: A new flexible multicomponent model for the study of aerosol dynamics in the marine boundary layer, Tellus, 63B, 1001-1025, 2011b.

Koornneef, J., van Keulen, T., Faaij, A., and Turkenburg, W.: Life cycle assessment of a pulverized coal power plant with postcombustion capture, transport and storage of $\mathrm{CO}_{2}$, Int. J. Greenhouse Gas Control, 2, 448-467, 2008.

Kurtén, T., Loukonen, V., Vehkamäki, H., and Kulmala, M.: Amines are likely to enhance neutral and ion-induced sulfuric acid-water nucleation in the atmosphere more effectively than ammonia, Atmos. Chem. Phys., 8, 4095-4103, doi:10.5194/acp8-4095-2008, 2008.
Kwok, E. S. C. and Atkinson, R.: Estimation of hydroxyl radical reaction rate constants for gas-phase organic compounds using a structure-reactivity relationship: An update. Atmos. Environ., 29, 1685-1695, 1995.

Landgraf, J. and Crutzen, P. J.: An efficient method for online calculations of photolysis and heating rates, J. Atmos. Sci., 55, 863878, 1998.

Lepaumier, H., Picq, D., and Carrette, P. L.: Degradation study of new solvents for $\mathrm{CO}_{2}$ capture in post-combustion, Greenhouse Gas Control Technologies 9, Proceedings of the 9th International Conference on Greenhouse Gas Control Technologies (GHGT9), 16-20 November 2008, Washington DC, USA, Energy Procedia, 1, 893-900, 2009.

Lloyd, J. A., Heaton, K. J., and Johnston, M. V.: Reactive uptake of trimethylamine into ammonium nitrate particles, J. Phys. Chem. A, 113, 4840-4843, 2009.

Mäkelä, J. M., Yli-Koivisto, S., Hiltunen, V., Seidl, W., Swietlicki, E., Teinila, K., Sillanpaa, M., Koponen, I. K., Paatero, J., Rosman, K., and Hameri, K.: Chemical composition of aerosol during particle formation events in boreal forest, Tellus B, 53, 380 393, 2001.

Meylan, W. and Howard, P. H.: User's Guide for APOWIN, Version 1.9. Syracuse Research Corporation, North Syracuse (NY), USA, 2000.

Meylan, W. M. and Howard, P. H.: A review of quantitative structure-activity relationship methods for the prediction of atmospheric oxidation of organic chemicals, Environ. Toxicol. Chem., 22, 1724-1732, 2003.

Mikoviny, T., Kaser, L., and Wisthaler, A.: Development and characterization of a High-Temperature Proton-Transfer-Reaction Mass Spectrometer (HT-PTR-MS), Atmos. Meas. Tech., 3, 537544, doi:10.5194/amt-3-537-2010, 2010.

Mirvish, S. S., Bulay, O., Runge, R. G., and Patil, K.: Study of the carcinogenicity of large doses of dimethylnitramine, N-nitroso1-proline and sodium nitrite administered in drinking water to rats, J. Natl. Cancer Inst., 64, 1435-1439, 1980.

Mozurkewich, M.: The dissociation constant of ammonium nitrate and its dependence on temperature, relative humidity and particle size, Atmos. Environ., 27A, 261-270, 1993.

Müller, M., George, C., and D'Anna, B.: Enhanced spectral analysis of C-TOF Aerosol Mass Spectrometer data: Iterative residual analysis and cumulative peak fitting, Int. J. Mass Spectrom., 306, $1-8,2011$.

Murphy, S. M., Sorooshian, A., Kroll, J. H., Ng, N. L., Chhabra, P., Tong, C., Surratt, J. D., Knipping, E., Flagan, R. C., and Seinfeld, J. H.: Secondary aerosol formation from atmospheric reactions of aliphatic amines, Atmos. Chem. Phys., 7, 2313-2337, doi:10.5194/acp-7-2313-2007, 2007.

Naumann, K. H.: COSIMA - a computer program simulating the dynamics of fractal aerosols, J. Aerosol Sci., 34, 1371-1397, 2003.

Nielsen, C. J., D’Anna, B., Dye, C., George, C., Graus, M., Hansel, A., Karl, M., King, S., Musabila, M., Müller, M., Schmidbauer, N., Stenstrøm, Y., and Wisthaler, A.: Atmospheric Degradation of Amines, Summary Report: Gas phase oxidation of 2aminoethanol (MEA), CLIMIT project no. 193438, NILU OR 8/2010, Norwegian Institute for Air Research, Kjeller, Norway, available at: http://www.nilu.no, 2010.

Nielsen, C. J., D’Anna, B., Dye, C., Graus, M., Karl, M., King, 
S., Musabila, M., Müller, M., Schmidbauer, N., Stenstrøm, Y., Wisthaler, A., and Pedersen, S.: Atmospheric chemistry of 2aminoethanol (MEA), Energy Procedia, 4, 2245-2252, 2011.

NVE, Carbon Capture and Storage at Kårstø, Svendsen P. T. (Ed.): Norwegian Water Resources and Energy Directorate, available at: http://www.nve.no, 2006.

Odum, J. R., Hoffmann, T., Bowman, F., Collins, D., Flagan, R. C., and Seinfeld, J. H.: Gas/particle partitioning and secondary organic aerosol yields, Environ. Sci. Technol., 30, 2580-2585, 1996.

Odum, J. R., Jungkamp, P. W., Griffin, R. J., Flagan, R. C., and Seinfeld, J. H.: The atmospheric aerosol-forming potential of whole gasoline vapor, Science, 276, 96-99, 1997.

Papa, E. and Gramatica, P.: Externally validated QSPR modeling of VOC tropospheric oxidation by $\mathrm{NO}_{3}$ radicals, SAR and QSAR in Environmental Research, 19, 655-668, 2008.

Piirilä, P., Nordman, H., Keskinen, H. M., Luukonen, R., Salo, S.P., Tuomi, T. O., and Tuppurainen, M.: Long-term follow-up of hexamethylene diisocyanate-, diphenylmethane diisocyanate, and Toluene diisocyanate-induced asthma, Am. J. Respir. Crit. Care Med., 162, 516-522, 2000.

Pitts, J. N., Grosjean, D., Vanmcauwenberghe, K., Schmidt, J. P. and Fitz, D. R.: Photooxidation of aliphatic amines under simulated atmospheric conditions: Formation of nitrosamines, nitramines, amides, and photochemical oxidant, Environ. Sci. Technol., 12, 946-953, 1978.

Press, W. H., Teukolsky, S. A., Vetterling, W. T., and Flanenry, B. P., Numerical Recipes in C, Cambridge University Press, Cambridge, United Kingdom, Chap. 15, 1992.

Puxty, G., Rowland, R., Allport, A., Yang, Q., Bown, M., Burns, R., Maeder, M., and Attalla, M.: Carbon dioxide post-combustion capture: a novel screening study of the carbon dioxide absorption performance of 76 amines, Environ. Sci. Technol., 43, 64276433, 2009.

Rao, A. B. and Rubin, E. S.: A technical, economic, and environmental assessment of amine-based $\mathrm{CO}_{2}$ capture technology for power plant greenhouse gas control, Environ. Sci. Technol., 36, 4467-4475, 2002.

Rochelle, G. T.: Amine scrubbing for $\mathrm{CO}_{2}$ capture, Science, 325, 1652-1653, 2009.

Ródenas, M.: Improvements in spectroscopy data processing: faster production and better reliability of Lab data, INTROP Report, available at: http://www.ceam.es/pag/contam_e_archivos/ MRodenasINTROPReport.pdf, last access: 19 July 2011, 2008.

Salo, K., Westerlund, J., Andersson, P. U., Nielsen, C. J., D’Anna, B., and Hallquist, M.: Thermal characterization of alkyl aminium nitrate nanoparticles. J. Phys. Chem. A, 115, 11671-11677, 2011.

Sander, R., Kerkweg, A., Jöckel, P., and Lelieveld, J.: Technical note: The new comprehensive atmospheric chemistry module MECCA, Atmos. Chem. Phys., 5, 445-450, doi:10.5194/acp-5445-2005, 2005.

Sander, R., Baumgaertner, A., Gromov, S., Harder, H., Jöckel, P., Kerkweg, A., Kubistin, D., Regelin, E., Riede, H., Sandu, A., Taraborrelli, D., Tost, H., and Xie, Z.-Q.: The atmospheric chemistry box model CAABA/MECCA-3.0, Geosci. Model Dev., 4, 373-380, doi:10.5194/gmd-4-373-2011, 2011.

Sander, S. P., Friedl, R. R., Golden, D. M., Kurylo, M. J., Moortgat, G. K., Keller-Rudek, H., Wine, P. H., Ravishankara, A. R.,
Kolb, C. E., Molina, M. J., Finlayson-Pitts, B. J., Huie, R. E., and Orkin, V. L.: Chemical Kinetics and Photochemical Data for Use in Atmospheric Studies, Evaluation Number 15, JPL Publication 06-2, Jet Propulsion Laboratory, Pasadena, CA, 2006.

Sandu, A. and Sander, R.: Technical note: Simulating chemical systems in Fortran90 and Matlab with the Kinetic PreProcessor KPP-2.1, Atmos. Chem. Phys., 6, 187-195, doi:10.5194/acp-6187-2006, 2006.

Sandu, A., Verwer, J. G., Van Loon, M., Carmichael, G. R., Potra, F. A., Dabdub, D., and Seinfeld, J. H.: Benchmarking stiff ODE solvers for atmospheric, chemistry problems .1. Implicit vs explicit, Atmos. Environ., 31, 3151-3166, 1997.

Scherf, H. R., Frei, E., and Wiessler, M.: Carcinogenic properties of $\mathrm{N}$-nitrodimethylamine and $\mathrm{N}$-nitromethylamine in the rat, Carcinogenesis, 10, 1977-1981, 1989.

Seinfeld, J. H. and Pandis, S. N., Atmospheric Chemistry and Physics: From Air Pollution to Climate Change, Chapter 9.4: Thermodynamics of Atmospheric Aerosol Systems, 534 pp., Wiley, New York, USA, 1998.

Seinfeld, J. H. and Pankow, J. F.: Organic atmospheric particulate material, Annu. Rev. Phys. Chem., 54, 121-140, 2003.

Sennbro, C. J., Lindh, C. H., Östin, A., Welinder, H., Jönsson, B. A. G., and Tinnerberg, H.: A Survey of airborne isocyanate exposure in 13 Swedish polyurethane industries. Ann. occup. Hyg., 48, 405-414, 2004.

Shah S. V., Apostolov, E. O., Ok, E., and Basnakian, A. G.: Novel mechanisms in accelerated atherosclerosis in kidney disease, J. Ren. Nut., 18, 65-69, 2008.

Smith, J. N., Barsanti, K. C., Friedli, H. R., Ehn, M., Kulmala, M., Collins, D. R., Scheckman, J. H., Williams, B. J., and McMurry, P. H.: Observations of aminium salts in atmospheric nanoparticles and possible climatic implications, Proc. Natl. Acad. Sci., 107, 66434-66439, 2010.

Sorooshian, A., Murphy, S. M., Hersey, S., Gates, H., Padro, L. T., Nenes, A., Brechtel, F. J., Jonsson, H., Flagan, R. C., and Seinfeld, J. H.: Comprehensive airborne characterization of aerosol from a major bovine source, Atmos. Chem. Phys., 8, 5489-5520, doi:10.5194/acp-8-5489-2008, 2008.

Suzuki, E., Mochizuki, M., Sekiguchi, N., Osabe, M., and Okada, M.: In vitro metabolism of N-nitrodialkylamines, Jpn. J. Cancer Res., 76, 28-36, 1985.

Thitakamol, B., Veawab, A., and Aroonwilas, A.: Environmental impacts of absorption-based $\mathrm{CO}_{2}$ capture unit for postcombustion treatment of flue gas from coal-fired power plant, Int. J. Greenhouse Gas Control, 1, 318-342, 2007.

Todeschini, R., Consonni, V., Mauri, A., and Pavan, M.: DRAGON version 6, Talete srl, Milan, Italy, available at: http://www.talete. mi.it/, 2011.

Tuazon, E. C., Carter, W. P. L., Atkinson, R., Winer, A. M., and Pitts, J. N., Jr.: Atmospheric reactions of $\mathrm{N}$-nitrosodimethylamine and dimethylnitramine, Environ. Sci. Technol., 18, 49-54, 1984.

US EPA, Estimation Programs Interface Suite ${ }^{\mathrm{TM}}$ for Microsoft Windows, v 4.00, United States Environmental Protection Agency, Washington, DC, Office of Pollution Prevention and Toxics, Syracuse (NY): Syracuse Research Corporation, available at: http://www.epa.gov/oppt/exposure/pubs/episuite.htm, 2009.

Veltman, K., Singh, B., and Hertwich, E. G.: Human and environmental impact assessment of postcombustion $\mathrm{CO}_{2}$ capture fo- 
cusing on emissions from amine-based scrubbing solvents to air, Environ. Sci. Technol., 44, 1496-1502, doi:10.1021/es902116r, 2010.

Vera, T., Muñoz, A., Ródenas, M., Vázquez, M., Borrás, E., Marqués, M., Mellouki, A., Treacy, J., and Sidebottom, H.: Atmospheric fate of hymexazol (5-methylisoxazol-3-ol): Simulation chamber studies, Atmos. Environ., 45, 3704-3710, 2011.
Wooldridge, S. T., Hanson, R. K., and Bowman, C. T.: A shock tube study of reactions of $\mathrm{CN}$ with $\mathrm{HCN}, \mathrm{OH}$, and $\mathrm{H}_{2}$ using $\mathrm{CN}$ and OH laser absorption, Int. J. Chem. Kinet., 28, 245-258, 1996.

Zádor, J., Turányi, T., Wirtz, K., and Pilling, M. J.: Measurement and investigation of chamber radical sources in the European Photoreactor (EUPHORE), J. Atmos. Chem., 55, 147-166, 2006. 